\title{
Evaluation of Electronic Monitoring Devices
}

Arnold G. Perrey

Barry A. Bell

Center for Electronics and Electrical Engineering

Electrosystems Division

Marshall J. Treado

Law Enforcement Standards Laboratory

U.S. DEPARTMENT OF COMMERCE

National Bureau of Standards

National Engineering Laboratory

Gaithersburg, MD 20899

December 1986

Prepared for

$-Q C \_$nal Institute of Justice

100 Department of Justice

.456

lington, DC 20531

$86-3501$

1986

C. 2 

NBSIR $86-3501$

\section{EVALUATION OF ELECTRONIC MONITORING DEVICES}

Arnold G. Perrey

Barry A. Bell

Center for Electronics and Electrical Engineering

Electrosystems Division

Marshall J. Treado

Law Enforcement Standards Laboratory

U.S. DEPARTMENT OF COMMERCE

National Bureau of Standards

National Engineering Laboratory

Gaithersburg, MD 20899

December 1986

Prepared for

National Institute of Justice

U.S. Department of Justice

Washington, DC 20531

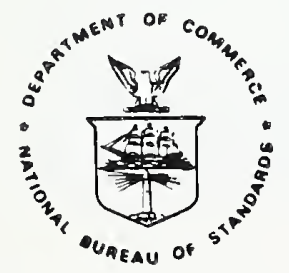

U.S. DEPARTMENT OF COMMERCE, Malcolm Baldrige, Secretary NATIONAL BUREAU OF STANDARDS, Ernest Ambler, Director 



\section{ABOUT THE TECHNOLOGY ASSESSMENT PROGRAM}

The Technology Assessment Program is sponsored by the office of Development, Testing, and Dissemination of the National Institute of Justice (NIJ), U.S. Department of Justice. The program responds to the mandate of the Justice System Improvement Act of 1979, which created NIJ and directed it to encourage research and development to improve the criminal justice system and to disseminate the results to Federal, State, and local agencies.

The Technology Assessment Program is an applied research effort that determines the technological needs of justice system agencies, sets minimum performance standards for specific devices, tests commercially available equipment against those standards, and disseminates the standards and the test results to criminal justice agencies nationwide and internationally.

The program operates through:

The Technology Assessment Program Advisory Council (TAPAC) consisting of nationally recognized criminal justice practitioners from Federal, State, and local agencies, which assesses technological needs and sets priorities for research programs and items to be evaluated and tested.

The Law Enforcement Standards Laboratory (LESL) at the National Bureau of Standards, which develops voluntary national performance standards for compliance testing to ensure that individual items of equipment are suitable for use by criminal justice agencies. The standards are based upon laboratory testing and evaluation of representative samples of each item of equipment to determine the key attributes, develop test methods, and establish minimum performance requirements for each essential attribute. In addition to the highly technical standards, LESL also produces user guides that explain in nontechnical terms the capabilities of available equipment.

The Technology Assessment Program Information Center (TAPIC) operated by a grantee, which supervises a national compliance testing program conducted by independent agencies. The standards developed by LESL serve as performance benchmarks against which commercial equipment is measured. The facilities, personnel, and testing capabilities of the independent laboratories are evaluated by LESL prior to testing each item of equipment, and LESL helps the Information Center staff review and analyze data. Test results are published in Consumer Product Reports designed to help justice system procurement officials make informed purchasing decisions.

Publications issued by the National Institute of Justice, including those of the Technology Assessment Program, are available from the National Criminal Justice Reference service (NCJRS), which serves as a central information and reference source for the Nation's criminal justice community. For further information on how to order, or to register with NCJRS, write to the National Institute of Justice, National Criminal Justice Reference Service, Washington, DC 20531.

James K. Stewart, Director National Institute of Justice 
This report was prepared by the Law Enforcement Standards Laboratory of the National Bureau of Standards under the direction of Lawrence K. Eliason, Chief of LESL. The laboratory work for this project was carried out by staff members of the NBS Electrosystems Division. The cooperation of the four manufacturers involved and the loan of their equipment for testing is gratefully acknowledged. The research was sponsored by the National Institute of Justice, Annesley K. Schmidt, Research Analyst. The technical effort to develop this report was conducted under Interagency Agreement LEAA-J-IAA-021-3, Project No. 8505. 
The Law Enforcement Standards Laboratory (LESL) of the National Bureau of Standards (NBS) furnishes technical support to the National Institute of Justice (NIJ) program to strengthen law enforcement and criminal justice in the United States. LESL's function is to conduct research that will assist law enforcement and criminal justice agencies in the selection and procurement of quality equipment.

LESL is: (1) Subjecting existing equipment to laboratory testing and evaluation and (2) conducting research leading to the development of several series of documents, including national voluntary equipment standards, user guides and technical reports.

This document presents the results of a two-step program to evaluate electronic monitoring devices that are intended for use in monitoring the presence of individuals within a given area who are responsible to the criminal justice system but not confined to institutions. As some of the testing was conducted in 1985, the manufacturers claim to have improved their equipment since then. In no case does the testing of this equipment imply the recommendation or endorsement of any product by the National Bureau of Standards, the National Institute of Justice or any other government agency.

Technical comments and suggestions concerning this document are invited from all interested parties. They should be addressed to the Law Enforcement Standards Laboratory, National Bureau of Standards, Gaithersburg, MD 20899.

Lawrence K. Eliason, Chief

Law Enforcement Standards Laboratory 

Page

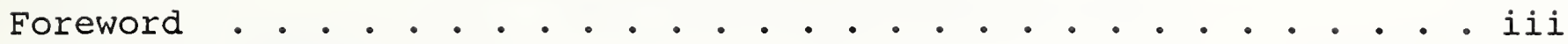

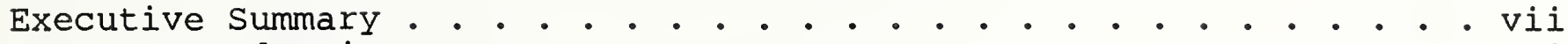

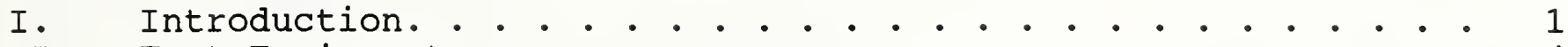

II. Test Equipment. . . . . • . . . . . . . . . . . . . . . . . . 4

III. Description and Evaluation - 1985 Tests . . . . . . . . . . 5

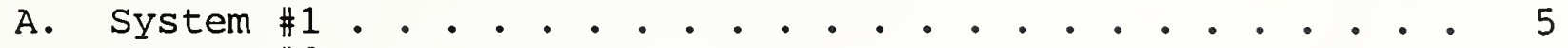

B. System \#2 . . . . . . . . . . . . . . . . . . . 22

IV. Description and Evaluation - 1986 Tests . . . . . . . . . . . 36

A. System \#3 . • . . . . . . . . . . . . . . . . . . . . 37

B. System \# 4 . . . . . . . . . . . . . . . . . . . . . . . . 40

V. Conclusions and Recommendations . . . . . . . . . . . . . . . . 47 


\section{COMMONLY USED SYMBOLS AND ABBREVIATIONS}

$\begin{array}{ll}\text { A } & \text { ampere } \\ \text { ac } & \text { alternating current } \\ \text { AM } & \text { amplitude modulation } \\ \mathrm{cd} & \text { candela } \\ \mathrm{cm} & \text { centimeter } \\ \mathrm{CP} & \text { chemically pure } \\ \mathrm{c} / \mathrm{s} & \text { cycle per second } \\ \mathrm{d} & \text { day } \\ \mathrm{dB} & \text { decibel } \\ \mathrm{dc} & \text { direct current } \\ { }^{\circ} \mathrm{C} & \text { degree Celsius } \\ { }^{\circ} \mathrm{F} & \text { degree Fahrenheit } \\ \mathrm{diam} & \text { diameter } \\ \mathrm{emf} & \text { electromotive force } \\ \text { eq } & \text { equation } \\ \mathrm{F} & \text { farad } \\ \mathrm{fc} & \text { footcandle } \\ \mathrm{fig} . & \text { figure } \\ \mathrm{FM} & \text { frequency modulation } \\ \mathrm{ft} & \text { foot } \\ \mathrm{ft} / \mathrm{s} & \text { foot per second } \\ \mathrm{g} & \text { acceleration } \\ \mathrm{g} & \text { gram } \\ \mathrm{gr} & \text { grain }\end{array}$

$\begin{array}{ll}\mathrm{H} & \text { henry } \\ \mathrm{h} & \text { hour } \\ \mathrm{hf} & \text { high frequency } \\ \mathrm{Hz} & \text { hertz }(\mathrm{c} / \mathrm{s}) \\ \mathrm{i} . \mathrm{d} . & \text { inside diameter } \\ \mathrm{in} & \text { inch } \\ \mathrm{ir} & \text { infrared } \\ \mathrm{J} & \text { joule } \\ \mathrm{L} & \text { lambert } \\ \mathrm{L} & \text { liter } \\ \mathrm{lb} & \text { pound } \\ \mathrm{lbf} & \text { pound-force } \\ \mathrm{lbf} \cdot \mathrm{in} & \text { pound-force inch } \\ \mathrm{lm} & \text { lumen } \\ \mathrm{ln} & \text { logarithm (natural) } \\ \mathrm{log} & \text { logarithm (common) } \\ \mathrm{M} & \text { molar } \\ \mathrm{m} & \text { meter } \\ \mathrm{min} & \text { minute } \\ \mathrm{mm} & \text { millimeter } \\ \mathrm{mph} & \text { mile per hour } \\ \mathrm{m} / \mathrm{s} & \text { meter per second } \\ \mathrm{N} & \text { newton } \\ \mathrm{N} \cdot \mathrm{m} & \text { newton meter }\end{array}$

$\begin{array}{ll}\text { nm } & \text { nanometer } \\ \text { No. } & \text { number } \\ \text { o.d. } & \text { outside diameter } \\ \Omega & \text { ohm } \\ \text { p. } & \text { page } \\ \text { Pa } & \text { pascal } \\ \text { pe } & \text { probable error } \\ \text { pp. } & \text { pages } \\ \text { ppm } & \text { part per million } \\ \text { qt } & \text { quart } \\ \text { rad } & \text { radian } \\ \text { rf } & \text { radio frequency } \\ \text { rh } & \text { relative humidity } \\ \text { s } & \text { second } \\ \text { SD } & \text { standard deviation } \\ \text { sec. } & \text { section } \\ \text { SWR } & \text { standing wave ratio } \\ \text { uhf } & \text { ultrahigh frequency } \\ \text { uv } & \text { ultraviolet } \\ V & \text { volt } \\ \text { vhf } & \text { very high frequency } \\ W & \text { watt } \\ \lambda & \text { wavelength } \\ \text { wt } & \text { weight }\end{array}$

area $=u_{n i t}{ }^{2}$ (e.g., $\mathrm{ft}^{2}$, in $^{2}$, etc.); volume $=u_{n i t}{ }^{3}\left(\right.$ e.g., $\mathrm{ft}^{3}, \mathrm{~m}^{3}$, etc.)

\section{PREFIXES}

$\begin{array}{ll}\text { d } & \text { deci }\left(10^{-1}\right) \\ \text { c } & \text { centi }\left(10^{-2}\right) \\ \text { m } & \text { milli }\left(10^{-3}\right) \\ \mu & \text { micro }\left(10^{-6}\right) \\ \text { n } & \text { nano }\left(10^{-9}\right) \\ \text { p } & \text { pico }\left(10^{-12}\right)\end{array}$

$\begin{array}{ll}\text { da } & \text { deka }(10) \\ \mathrm{h} & \text { hecto }\left(10^{2}\right) \\ \mathrm{k} & \text { kilo }\left(10^{3}\right) \\ \mathrm{M} & \text { mega }\left(10^{6}\right) \\ \mathrm{G} & \text { giga }\left(10^{9}\right) \\ \mathrm{T} & \text { tera }\left(10^{12}\right)\end{array}$

\section{COMMON CONVERSIONS}

(See ASTM E380)
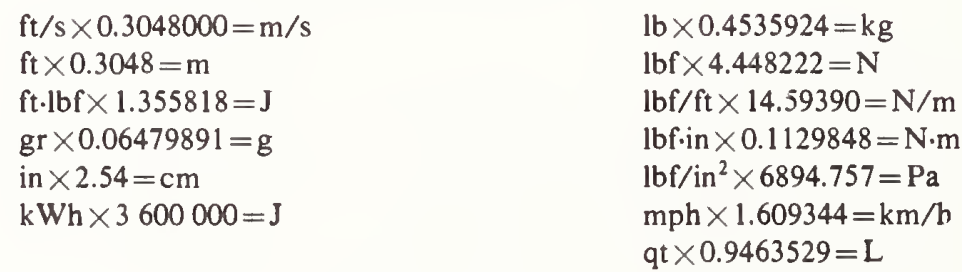

Temperature: $\left(T_{{ }_{F}}-32\right) \times 5 / 9=T_{C_{C}}$

Temperature: $\quad\left(T_{\mathrm{C}} \times 9 / 5\right)+32=T_{\mathrm{F}_{\mathrm{F}}}$ 
Through the use of electronic monitoring devices (EMDs), persons convicted of certain crimes may be sentenced to home confinement, thereby reducing both the cost and social implications associated with institutional confinement. Accordingly, a strong case can be made for the use of EMDs by many jurisdictions in this country. In view of their possible widespread use, the National Institute of Justice asked the National Bureau of Standards to develop a test plan and conduct tests of these devices to measure (1) their advertised basic technical characteristics, and (2) other operational characteristics such as range, safety, compatibility between system components, and tamper resistance.

All known manufacturers of EMDs were contacted but only two companies were willing to submit their systems for testing in 1985. The systems (transmitter and receiver/monitor) were tested in an open field, wooden residence, metal building and a laboratory environment. Both systems performed as advertised with respect to operating frequency, range of operation, and waterproof characteristics. Differences between the two were due primarily to frequency band considerations. Both systems have relatively low effective radiated output powers, making them susceptible to reduced operating range in the vicinity of certain configurations of metal objects and broadcast electromagnetic interference (EMI). Conversely, they were not bothered by EMI from typical household products. Reduced operating range also resulted when the individual wearing the transmitter shielded it from direct line of sight to the receiver/monitor, substantially reducing the received signal in one instance. Neither system was found to be unsafe during these limited tests and, when called upon to do so, transmitted a different signal than that for normal operation.

Two additional companies submitted equipment for testing in 1986 , and their transmitters and receiver/monitors were tested in a similar fashion. Both of these systems also met their stated goals as to operating frequency, range of operation, and waterproof characteristics. Neither system was found to be unsafe during these limited tests, and the one that had a tamper capability transmitted a different signal when tampered with. Because of low effective output power, both systems would be susceptible to interference in the vicinity of broadcast transmitters. For additional information on the test results for each of these four systems, please refer to the summaries at the conclusion of each series of tests: page 20 for system \#1, page 34 for system \#2, page 37 for system \#3, and page 42 for system \#4. 

Evaluation of Electronic Monitoring Devices

Arnold G. Perrey, "Barry A. Bell, * and Marshall J. Treado** National Bureau of Standards, Gaithersburg, MD 20899

Electronic Monitoring Devices (EMDs) are used to monitor the presence of individuals within a given area who are responsible to the criminal justice system but not confined to institutions. Several EMDs were tested to measure operational characteristics such as operating frequency. approximate range of operation, component capability, and tamper resistance. Tests were conducted in an open field, wooden residence, high rise metal building, and in a laboratory environment.

Key words: early release; electromagnetic interference; electronic monitoring; monitoring device; parole; receiver/ monitor; tamper resistance; transmitter.

\section{INTRODUCTION}

Several manufacturers have developed equipment that is intended to be used to monitor the presence of individuals within a given area who are responsible to the criminal justice system but not confined to institutions. This equipment, referred to as Electronic Monitoring Devices (EMDs), is intended to permit law enforcement agencies to determine, on a timely basis, whether persons on noninstitutional confinement are in compliance with the terms of their agreement.

Through the use of EMDs, persons convicted of nonviolent crime may be sentenced to home confinement, thereby reducing both the cost and social implications associated with institutional confinement. Jurisdictions with a lack of space that elect to enter into an early release program may also want to use EMDs to monitor the status of parolees in such a program. A study by the U.S. Department of Justice estimates that there are $1.827 \mathrm{M}$ persons in the United States on probation or parole, and it is further estimated that about $8 \mathrm{M}$ people nationally are convicted of misdemeanors at the state and local government levels each year. Very few of these individuals ever serve time in jail. Proponents of the use of EMDs by the criminal justice system believe that certain monetary savings will result, as the cost to monitor an individual will be significantly less than the cost to house, feed, and rehabilitate the same person. There are also projected savings in lost wages and productivity, as well as a decrease in the need for additional correctional facilities. Thus, a strong case can be made for the use of EMDs by most jurisdictions.

*Electrosystems Division, Center for Electronics and Electrical Engineering, National Engineering Laboratory. Laboratory.

** Law Enforcement Standards Laboratory, National Engineering 
As the possible need for EMDs became apparent, several different models were proposed and at least two were evaluated in typical probation situations, one in New Mexico and Illinois, and a second in Florida. Several other manufacturers have come forth in response to written and verbal solicitations, saying that they intend to produce a product capable of monitoring persons on noninstitutional confinement.

At the request of the National Institute of Justice (NIJ), the National Bureau of Standards (NBS), through its Law Enforcement Standards Laboratory (LESL) and the Electrosystems Division, has evaluated the performance of EMDs with an emphasis on the technical properties and operational characteristics of the equipment. All known manufacturers of EMDs were contacted to obtain information on the technical characteristics of these devices and the results of any prior testing of components or of complete systems. Typical systems usually consist of three major components: a transmitting device worn by the individual, the receiver/monitor device that plugs into household power and transmits a signal via a standard telephone line, and a computer terminal at the central headquarters location that receives and displays this signal. A test plan, developed by LESL, was used to measure the basic technical characteristics of the transmitter and the receiver/monitor and to measure operational characteristics such as safety, range, compatibility, and tamper resistance.

The EMD evaluation program was advertised in the Commerce Business Daily and all known manufacturers were asked to send in equipment for evaluation. The following two companies voluntarily submitted their equipment for testing in 1985: Monitech Systems, Inc., 3269 South Main, suite 210, Salt Lake City, UT 84115, and Contrac Company, P.O. Box 427, Key Largo, FL 33037. Two others, Correction Services, Inc. (CSI), P.O. Box 2941, West Palm Beach, FI 33402, and Control Data Corporation (CDC), 7600 France Avenue South, Edina, MN 55435, submitted their equipment for testing about a year later. The CDC system is now being handled by Boulder Industries of 6175 Longbow Drive, Boulder, Co 33402 .

In the following report, the respective units are described and documented by the order in which they were received. Hence, the Monitech system (now known as computrac) is referred to as system \#1, Contrac as system \#2, CSI as system \#3, and CDC as system \#4. Tests were conducted in four locations. The four locations are shown in figure 1, which depicts the NBS Gaithersburg, MD campus:

${ }^{1}$ In order to adequately describe the systems and experiments discussed in this report, commercial equipment and instruments are identified by manufacturer's name or model number. In no case does such identification imply recommendation or endorsement by the National Bureau of Standards, the National Institute of Justice or any other government agency, nor does it imply that the material or equipment identified is necessarily the best available for the purpose. 


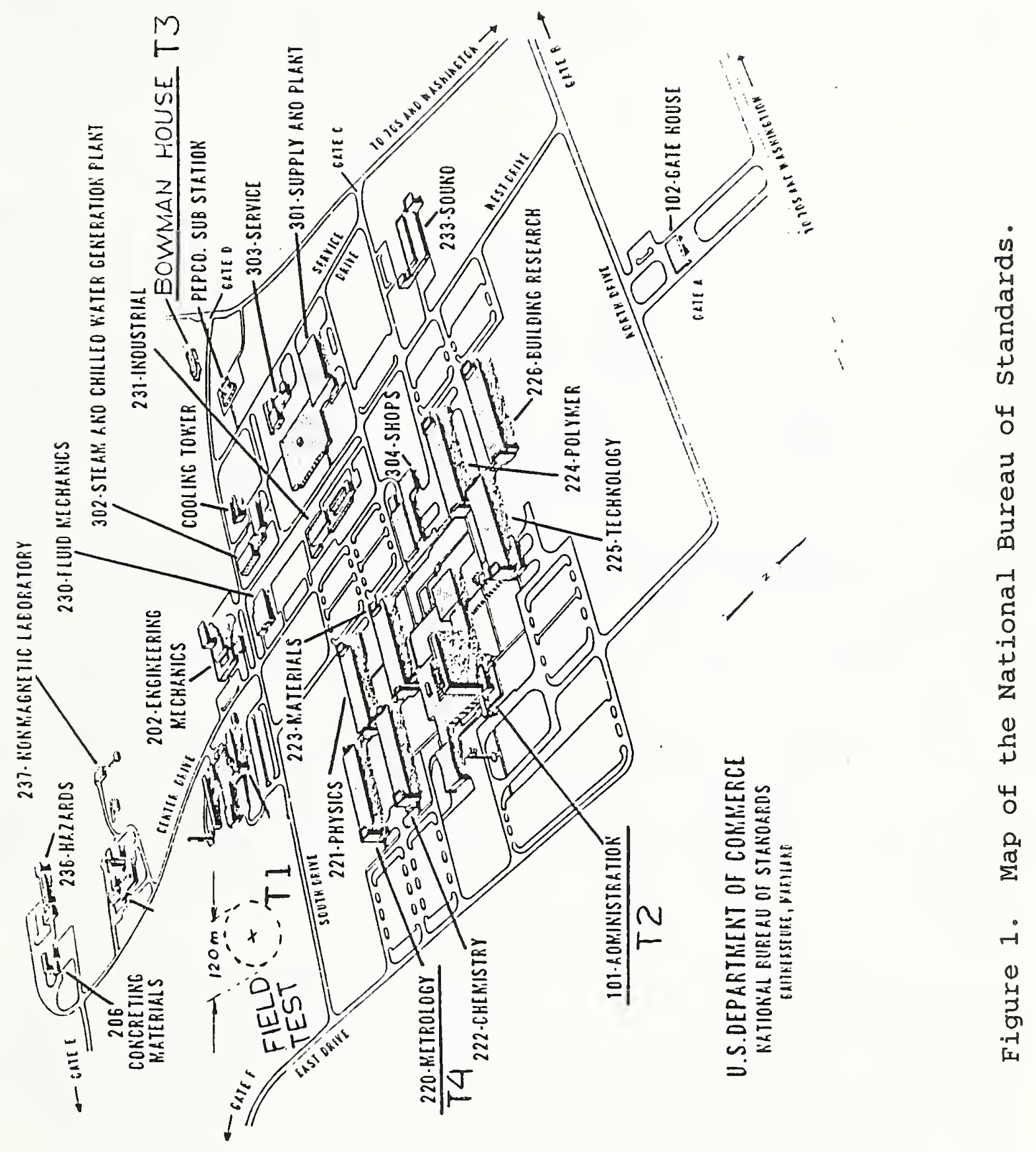


Test Locations $\mathrm{TI}=$ open field test area

$\mathrm{T} 2$ = Administration Building

$\mathrm{T} 3$ = Bowman House

$\mathrm{T} 4$ = Metrology Building

In analyzing the data in the tables, the reader should know that a 6 $\mathrm{dB} / \mu \mathrm{V}$ reduction in signal strength means a loss of approximately one-half the transmitter output power and that a $1 \mathrm{~dB} / \mu \mathrm{V}$ received signal is considered marginal, i.e., not sufficient to guarantee reception if atmospheric or environmental conditions change.

\section{TEST EQUIPMENT}

Five major items of test equipment were used in these tests. An EMI/field intensity meter was used for all field strength tests. This instrument can be used in a manual or programmable mode for measuring electromagnetic interference (EMI) emissions within a frequency range from $30 \mathrm{MHz}$ to $1.0 \mathrm{GHz}$ in accordance with specifications of MIL standard 461A. The direct peak pulse measurement mode was used to evaluate the system performance. In this mode the instrument provides a detector function that responds to the peak value of the input signal. Since these systems transmit rather short pulses, a peak hold duration of $0.05 \mathrm{~s}$ was chosen. The system bandwidth was limited to 0.1 $\mathrm{MHz}$ for satisfactory noise reduction.

A biconical dipole antenna was used to test system \#1 which has a carrier frequency just below $170 \mathrm{MHz}$. This antenna is a broadband, horizontally-polarized antenna designed to cover the frequency range from $25 \mathrm{MHz}$ to $200 \mathrm{MHz}$, and is calibrated for a 50- $\Omega$ load. The antenna unit is specifically designed for measurement of radiated emissions and meets MIL standard 461 A requirements.

A conical log periodic spiral antenna was used to test systems 2, 3 , and 4 which have carrier frequencies in the range of $310-325 \mathrm{MHz}$. It is a broadband antenna operating over the frequency range of $200 \mathrm{MHz}$ to $1 \mathrm{GHz}$. The antenna has a nominal 50- $\Omega$ impedance and meets the requirements of MIL Standard 461A. A log spiral antenna is circularly polarized, assuring equal response to signals radiated in either the horizontal or vertical plane.

A spectrum analyzer in an oscilloscope mainframe was used to document the pulse signatures of the transmitters under test. The unit is capable of operating over a frequency range from $1 \mathrm{kHz}$ to $1.8 \mathrm{GHz}$. In order to photograph the transmitted pulses, a custom-designed pickup coil was used to connect to the spectrum analyzer input. This pickup coil allowed close proximity coupling between the spectrum analyzer and the transmitters under test.

An oscilloscope camera with Polaroid film was used to photograph pulse waveforms and codes of the equipment tested. All pictures taken were taken with a time exposure which varied from 10 to 50 s for individual frames. 
A. SYSTEM \#1

The system \#1 equipment consisted of:

1) Telemetry receiver

\#101884-1238

2) Digital processor

\#101884-186

3) Miniature transmitter \#251

4) Miniature transmitter \#264

A photograph of these components is given in figure 2. The test equipment in the background is not part of the system.

The Equipment

1. Transmitters

A close-up photograph of the miniature transmitters is shown in figure 3, and the physical dimensions of these devices are shown in figure 4. This particular type of transmitter is worn around the neck on a loop that is approximately $15 \mathrm{~cm}$ ( $6 \mathrm{in}$ ) in diameter. The loop serves two purposes: a) physical support of the transmitter, and b) electrical control of the transmitting mode. When an individual is being outfitted with a transmitter, the loop has to be opened; then it is closed around the neck by means of a pin contact feature. The loop itself consists of 50 strand, 32-gage stainless steel wires that electrically connect to the internal power source and the active transmitting circuit.

The transmitter can be deactivated by attaching a small permanent magnet to its case. It transmits a burst of radio frequency for a predetermined time $(\sim 20 \mathrm{~ms})$. The transmitter operates using two time periods. The nominal time between bursts is either 1 s or 2 s depending on whether the attachment loop is electrically open or closed.

Measured transmitting parameters differed slightly between transmitters as indicated below:

Transmitter \#251

Transmitter \#264

Operating frequency:

Toneburst duration:

Period 1 nominal:

Period 1 actual:

Period 2 nominal:

Period 2 actual:
$168.922 \mathrm{MHz}$

$\sim 25 \mathrm{~ms}$

1 s (open loop)

$0.897 \mathrm{~s}$

2 s (closed loop)

$2.075 \mathrm{~s}$
$168.989 \mathrm{MHz}$

$\sim 24 \mathrm{~ms}$

$1 \mathrm{~s}$ (open loop)

$1.251 \mathrm{~s}$

2 s (closed loop)

$2.414 \mathrm{~s}$

2. Monitor

The monitor station as received consisted of two items, a receiver which is ordinarily used for telemetry purposes, and a digital processor. The physical dimensions and external features of these items are shown in figure 4. A telephone interface was not provided. Upon receipt of a signal from the transmitter, the receiver provides 


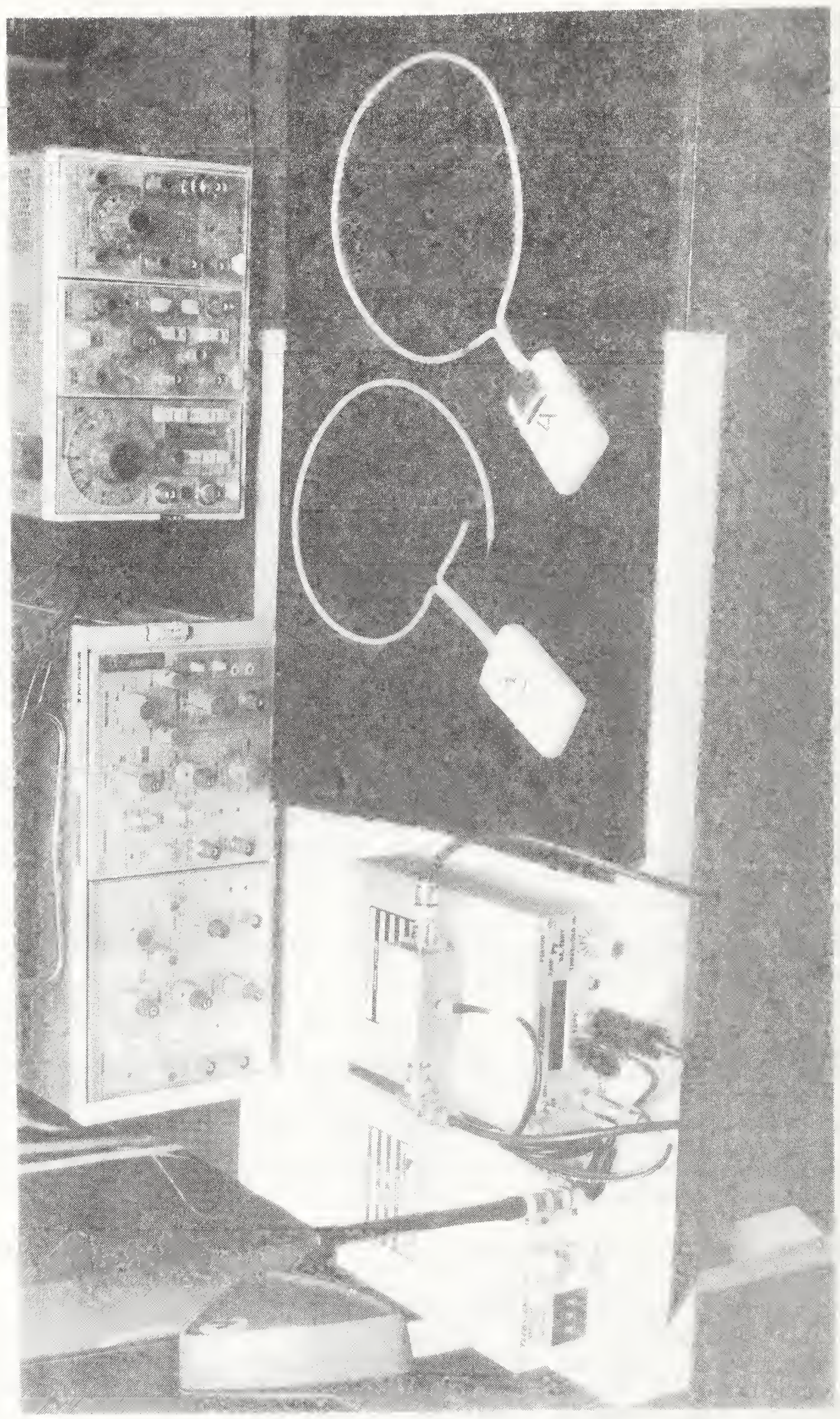

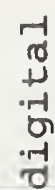

E

त)

$\infty$

$m \in$

$\mathrm{N} N$

H

I

$\infty$

$\infty+$

rt t.

엄됴

\#

म4 त्र

$\rightarrow E$

$0=$

0

it

>

4

(1)

ำ

-

$+4$

$0+$

단

E

F

म

i. E-

$+$

जิm

$\rightarrow$

4

0

1

$+\nabla$

(1) $\infty$

-1

동

.

w 4

in

\#

E $O$

ए)

ज

$\dot{\sim}$

(1)

늠

O 


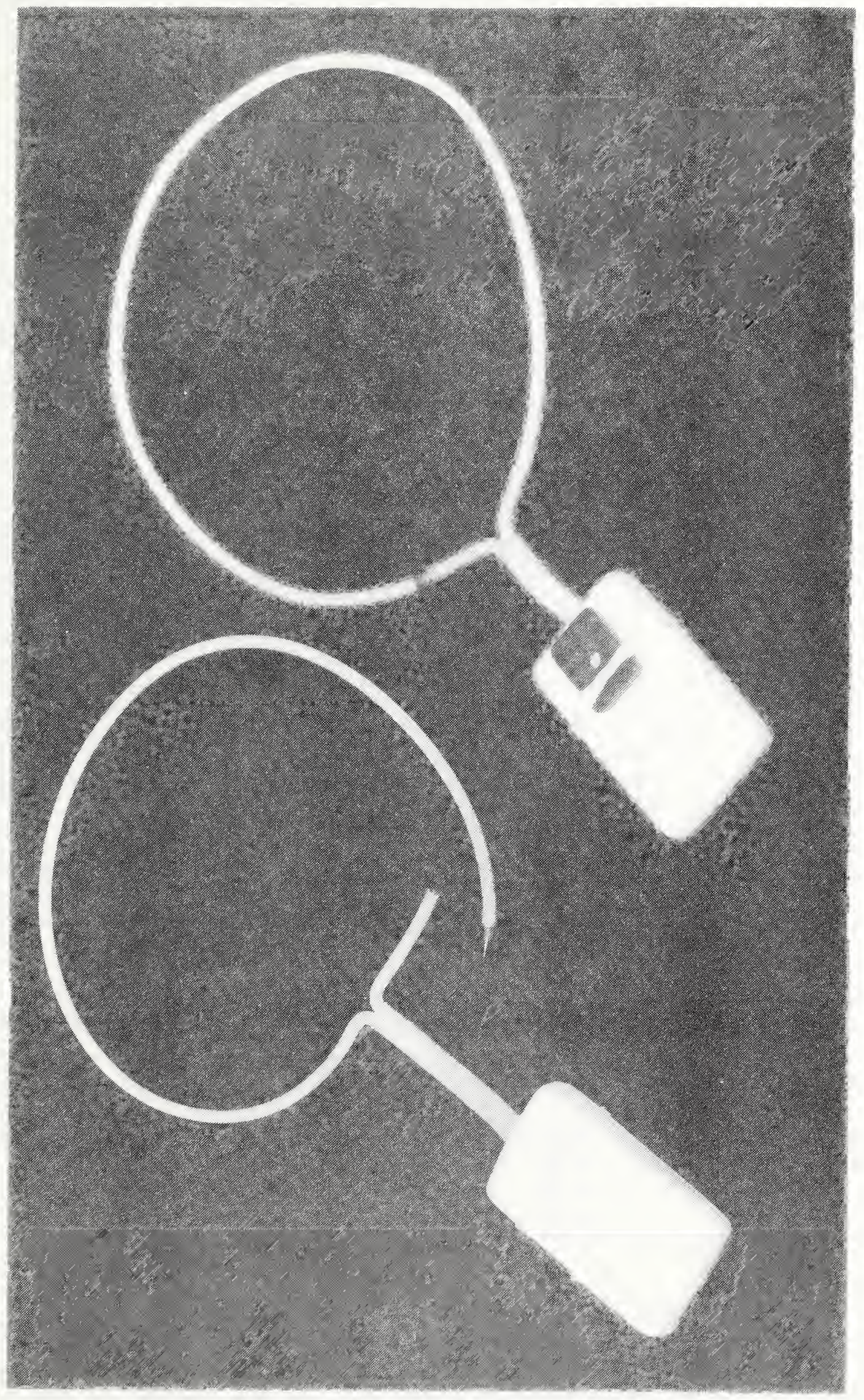

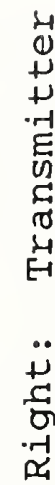

蛋

$N$

a

$\infty$

-1

0

$4-1$

-i

เก

\#歪

$4 \infty$

(1)

$+\infty$

$-1 \infty$

ह

政

क्ष

E

芦岕

 


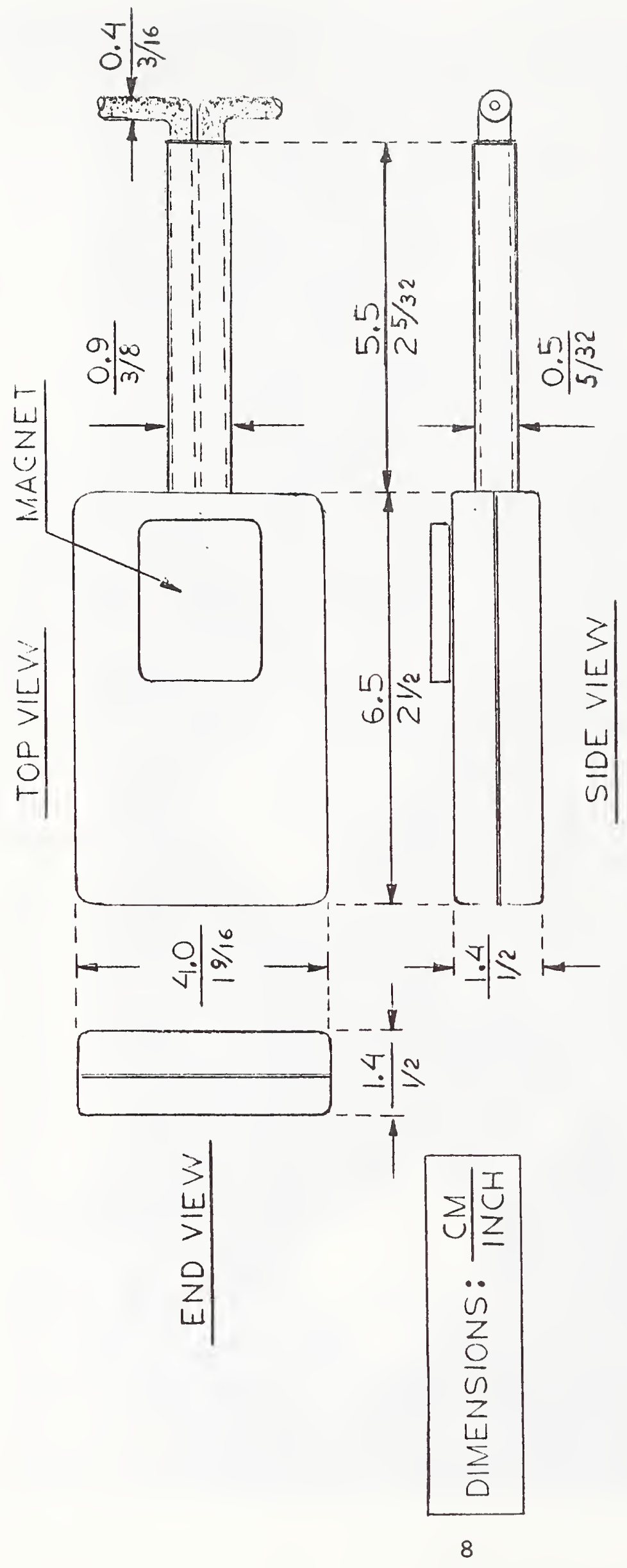

ت-1 
amplitude and frequency information to equipment such as the digital processor. Its input impedance is $50 \Omega$ and it has a built-in speaker which automatically disconnects when a headset is used. The headset jack is also used as a means to connect the receiver to the digital processor, in this application. Receiver tuning and level controls are on the front panel along with the antenna connection, battery charge input, and battery status indicator.

Upon receipt of the signal from the receiver, the digital processor measures and stores it until the next pulse is received. The stored level can be recorded or displayed as needed, as can the period between pulses. Amplitude or period displays can be selected using the mode selector switch. Amplitude is displayed as a current between 0-1 $\mathrm{mA}$, while the period between pulses can range from $0.2 \mathrm{~s}$ to $9.999 \mathrm{~s}$. The processor is battery powered, with a battery status indicator on the panel. The battery is rechargeable.

\section{Transmitter Testing}

The following is the performance data for transmitters \#251 and \#264 from measurements taken in locations $T 1$ through $T 4$. The field intensity meter and biconical dipole antenna were used for the tests in all four locations. The antenna correction Eactor for these tests is $14.5 \mathrm{~dB}$. Field strengths were measured in decibels referenced to one microvolt $(\mathrm{dB} / \mu \mathrm{V})$ and converted to microvolts per meter $(\mu \mathrm{V} / \mathrm{m})$, taking into account the antenna correction factor.

These data provide a baseline of information about the inherent field strength of these two transmitters as a function of radial distance from the transmitter. Table 1 gives the results of tests conducted in the open field test site with the monitor placed on the ground and each transmitter, in turn, moved to locations 10, 20, 30, 40 , and $50 \mathrm{~m}(32.8,65.6,98.4,131.2$, and $164 \mathrm{ft})$ from the monitor. Transmitters were worn by an individual facing the monitor at a height of approximately $1.2 \mathrm{~m}$ ( $4 \mathrm{ft})$ above the ground. Any measurement of approximately $1 \mathrm{~dB} / \mu \mathrm{V}$ or less (about $40 \mathrm{~m}$ from the monitor, in this case) is considered marginal (not reliable) reception.

Table 1. System $\|_{1} 1$ measurements at the open field test site

Transmitter 非251

\begin{tabular}{lll}
\hline Radius & $\mathrm{dB} / \mu \mathrm{V}$ & $\mu \mathrm{V} / \mathrm{m}$ \\
$10 \mathrm{~m}$ & +4.0 & 8.2 \\
$20 \mathrm{~m}$ & +3.0 & 7.5 \\
$30 \mathrm{~m}$ & +2.5 & 7.1 \\
$40 \mathrm{~m}$ & +1.1 & 6.0 \\
$50 \mathrm{~m}$ & -1.0 & 4.7
\end{tabular}

Transmitter 非264

\begin{tabular}{lll}
\hline Radius & $\mathrm{dB} / \mu \mathrm{V}$ & $\mu \mathrm{V} / \mathrm{m}$ \\
$10 \mathrm{~m}$ & +3.0 & 7.5 \\
$20 \mathrm{~m}$ & +2.0 & 6.7 \\
$30 \mathrm{~m}$ & +1.5 & 6.4 \\
$40 \mathrm{~m}$ & +1.0 & 5.9 \\
$50 \mathrm{~m}$ & -1.6 & 4.4
\end{tabular}

At a distance of $40 \mathrm{~m}(131.2 \mathrm{ft})$ an attenuation in field strength of approximately $15 \mathrm{~dB}$ was measured when the person wearing the transmitter turned his back towards the antenna. A 15 dB decrease in field strength means that more than $3 / 4$ of the signal level was lost. This decrease is probably caused by body bulk or capacitance or both. 
There was no interference from citizens band radios or police radios operating at typical police frequency bands, nor was there any interference from impulsive noise such as that generated by motor brushes or automobile engines.

Tests were conducted with the monitor placed on the floor in one section of the lobby of the Administration Building and each transmitter, in turn, moved to locations $10,20,30,40$, and $50 \mathrm{~m}$ $(37.8,65.6,98.4,131.2$, and $164 \mathrm{ft})$ away at a height of approximately $1.2 \mathrm{~m}(4 \mathrm{ft})$ off the ground. Again, the transmitters were worn by an individual who faced the monitor. See figure 5 for the layout of the lobby floor of the Administration Building. The designation TP was given to the test position, the location of the receiving antenna and the field strength meter. Table 2 contains data taken at designated distances along the straight line path from the test position.

Table 2. System $\# 1$ measurements in the Administration Building

Transmitter 非251

\begin{tabular}{lll}
\hline Radius & $\mathrm{dB} / \mu \mathrm{V}$ & $\mu \mathrm{V} / \mathrm{m}$ \\
$10 \mathrm{~m}$ & +4.0 & 8.2 \\
$20 \mathrm{~m}$ & +3.5 & 8.0 \\
$30 \mathrm{~m}$ & +3.0 & 7.5 \\
$40 \mathrm{~m}$ & +2.0 & 6.7 \\
$50 \mathrm{~m}$ & +1.5 & 6.4 \\
Third & & \\
F1oor & +1.0 & 5.9
\end{tabular}

Transmitter 非264

\begin{tabular}{lll}
\hline Radius & $\mathrm{dB} / \mu \mathrm{V}$ & $\mu \mathrm{V} / \mathrm{m}$ \\
$10 \mathrm{~m}$ & +3.5 & 8.0 \\
$20 \mathrm{~m}$ & +3.0 & 7.5 \\
$30 \mathrm{~m}$ & +3.0 & 7.5 \\
$40 \mathrm{~m}$ & +2.0 & 6.7 \\
$50 \mathrm{~m}$ & +1.8 & 6.5 \\
Third & & \\
Floor & +1.0 & 5.9
\end{tabular}

Compared to the open field data, the reception at this inside (lobby) location is somewhat greater (about $0.5 \mathrm{~dB} / \mu \mathrm{V}$ ) for a given radial distance from the transmitter. Entrance into an elevator located approximately $10 \mathrm{~m}(32.8 \mathrm{ft})$ from the monitor resulted in a complete loss of signal when the elevator door was closed. Reception on a given corridor level, up to a distance of $50 \mathrm{~m}$ (164 ft), was about the same as given in the table above. A measurement taken while the transmitter was located on the third floor (two floors above the monitor location) near the elevator shaft is given in the table. However, reception with the transmitters located above the third floor was marginal $(<+1 \mathrm{~dB} / \mu \mathrm{V})$. This is probably due to the amount of steel in this building, as it has all metal walls, except as indicated in figure 5. Strong interference from the NBS security Communication System located in the basement of the building (one floor below the lobby) generated a field strength of $3 \mathrm{~V} / \mathrm{m}$ at the test station. Total masking of the signal from the low power transmitters occurred when the security communication system was being used. The carrier frequency of the NBS security system is about $168 \mathrm{MHz}$.

The Bowman House is located on the NBS campus and is surrounded by tall oak trees. The building is of all wood construction and features a typical residential layout (see fig. 6). The numbers indicate successive transmitter positions relative to the test position. Underlined numbers indicate basement locations. The data in table 3 indicate that maximum reception was obtained in locations 5 and 6 where 


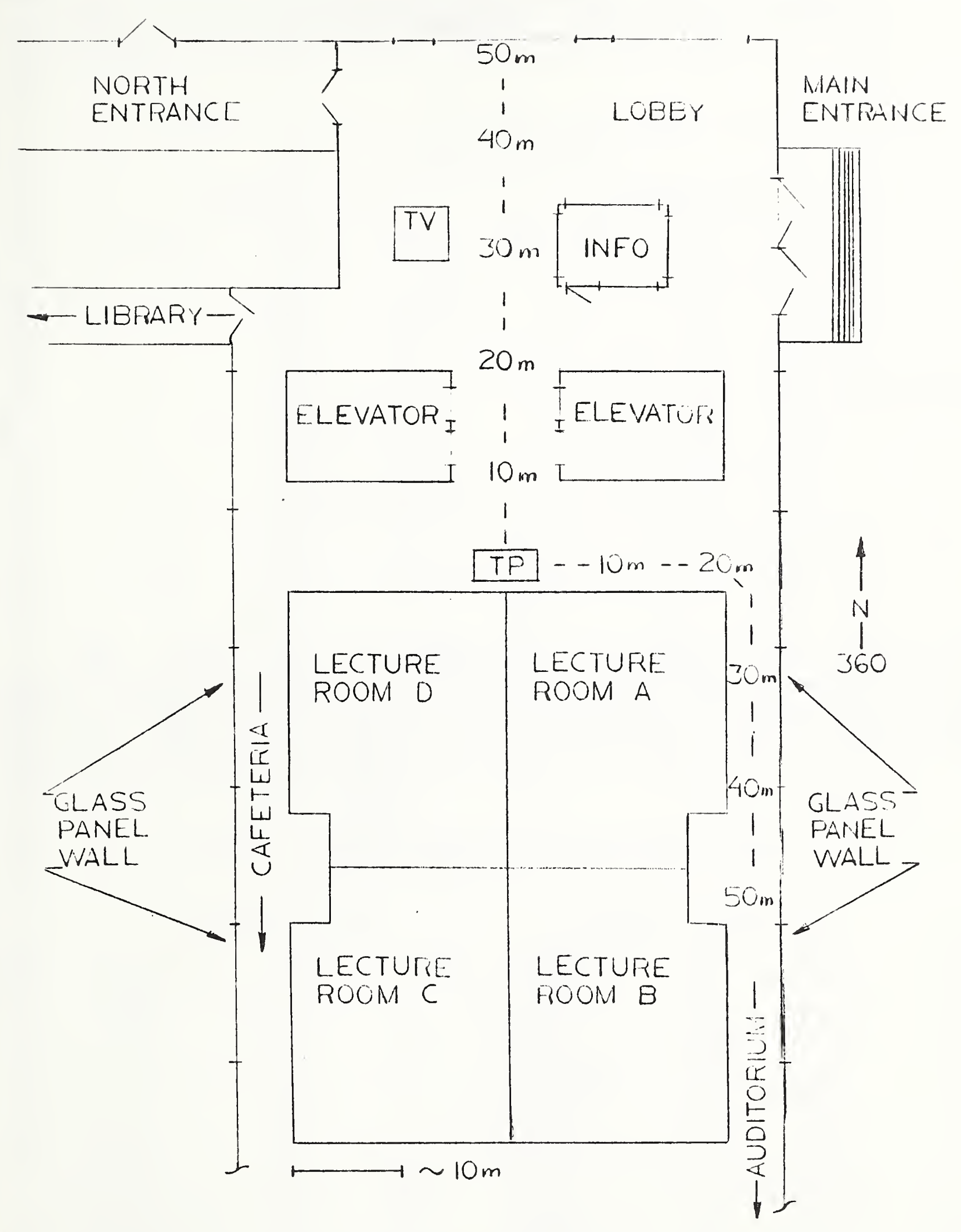

Figure 5. Layout of the lobby area, NBS Administration Building. 


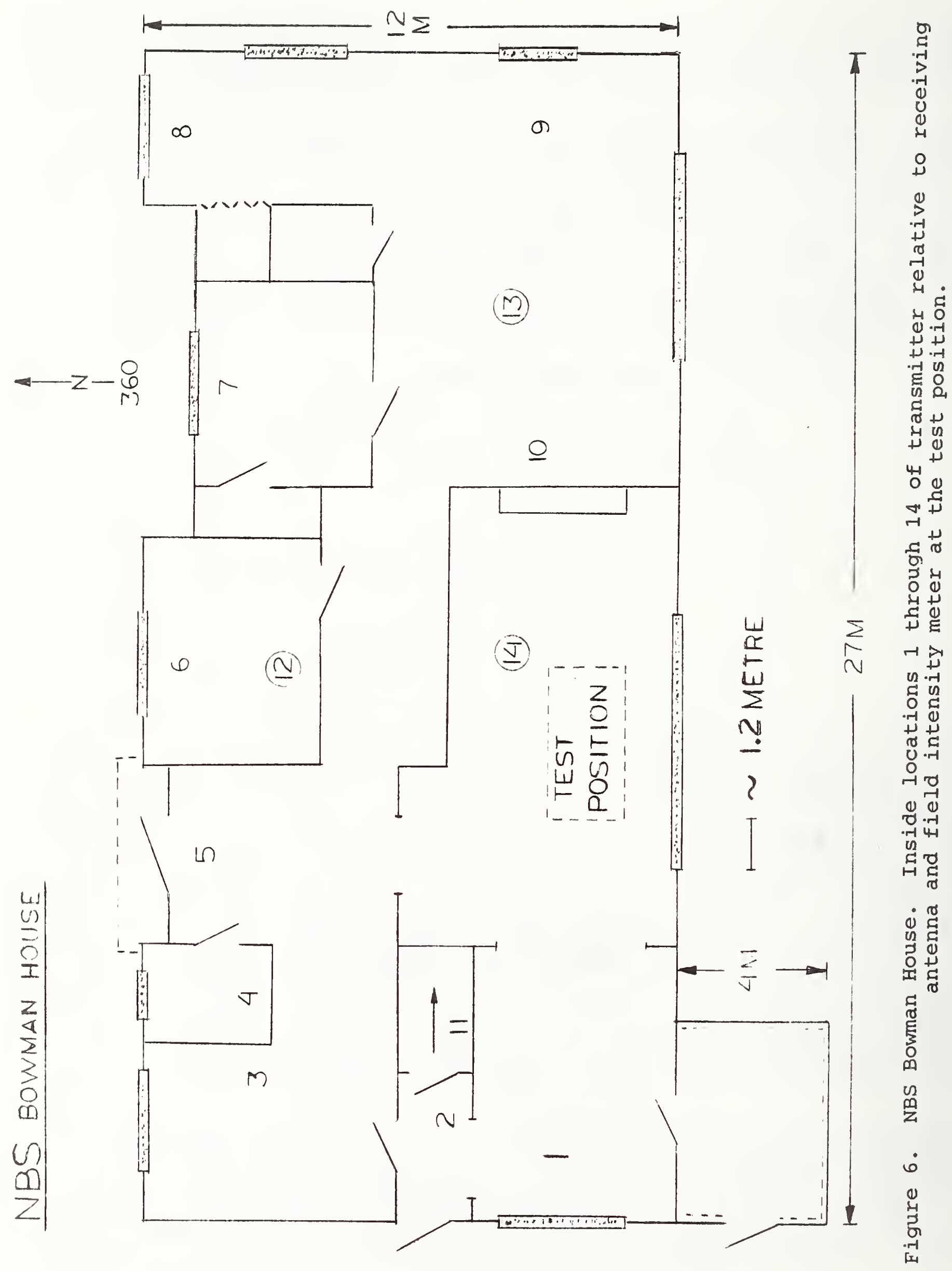


the fewest wall obstructions existed between the transmitters and the receiving antenna/field strength meter test setup. Locations 11, 12, 13 , and 14 in the stairwell and basement had decreased reception due to heating and air conditioning ductwork, flooring, etc.

Table 3. System $\|_{1} 1$ measurements at the Bowman House

(inside locations 1 through 14)

Transmitter 非251

Location

1
2
3
4
5
6
7
8
9
10
11
$\frac{12}{13}$
$\underline{14}$

$\begin{array}{ll}\mathrm{dB} / \mu \mathrm{V} & \mu \mathrm{V} / \mathrm{m} \\ +4.5 & 8.9 \\ +4.5 & 8.9 \\ +4.5 & 8.9 \\ +4.0 & 8.2 \\ +5.0 & 9.2 \\ +5.0 & 9.2 \\ +4.0 & 8.2 \\ +3.0 & 7.5 \\ +3.0 & 7.5 \\ +4.0 & 8.2 \\ +3.0 & 7.5 \\ +3.0 & 7.5 \\ +3.0 & 7.5 \\ +3.0 & 7.5\end{array}$

Transmitter 非264

\begin{tabular}{ccc}
\hline Location & $\mathrm{dB} / \mu \mathrm{V}$ & $\mu \mathrm{V} / \mathrm{m}$ \\
1 & +4.0 & 8.2 \\
2 & +3.0 & 7.5 \\
3 & +3.0 & 7.5 \\
4 & +3.5 & 8.0 \\
5 & +4.0 & 8.2 \\
6 & +4.0 & 8.2 \\
7 & +3.0 & 7.5 \\
8 & +3.0 & 7.5 \\
9 & +2.0 & 6.7 \\
10 & +3.0 & 7.5 \\
11 & +3.0 & 7.5 \\
$\frac{12}{13}$ & +2.0 & 6.7 \\
$\frac{14}{14}$ & +2.0 & 6.7 \\
& +2.0 & 6.7
\end{tabular}

The data in table 4 were obtained from readings taken outside the Bowman House at successive locations, 15 through 18-2, relative to the test position (see fig. 7). These positions represent the maximum possible normal range of operation in the vicinity of the Bowman House which is enclosed on three sides by a chain link fence and surrounded by tall foliated trees.

Table 4. System $\# 1$ measurements at the Bowman House (outdoor locations 15 through 18)

Transmitter 非251

\begin{tabular}{lll}
\hline Location & $\mathrm{dB} / \mu \mathrm{M}$ & $\mu \mathrm{V} / \mathrm{m}$ \\
& & \\
West 15 & +2.0 & 6.7 \\
$15-1$ & +2.0 & 6.7 \\
$15-2$ & +2.5 & 7.1 \\
South 16 & +2.5 & 7.1 \\
16-1 & +2.5 & 7.1 \\
$16-2$ & +2.5 & 7.1 \\
East 17 & +2.5 & 7.1 \\
$17-1$ & +2.5 & 7.1 \\
$17-2$ & +1.0 & 5.9 \\
North 18 & +2.5 & 7.1 \\
$18-1$ & +2.5 & 7.1 \\
$18-2$ & +2.5 & 7.1
\end{tabular}

Transmitter 非264

\begin{tabular}{lll}
\hline Location & $\mathrm{dB} / \mu \mathrm{V}$ & $\mu \mathrm{V} / \mathrm{m}$ \\
& & \\
West 15 & +1.5 & 6.4 \\
$15-1$ & +1.5 & 6.4 \\
$15-2$ & +2.5 & 7.1 \\
South 16 & +2.5 & 7.1 \\
$16-1$ & +2.5 & 7.1 \\
$16-2$ & +2.5 & 7.1 \\
East 17 & +2.5 & 7.1 \\
$17-1$ & +2.5 & 7.1 \\
$17-2$ & +1.0 & 5.9 \\
North 18 & +2.0 & 6.7 \\
$18-1$ & +2.0 & 6.7 \\
$18-2$ & +2.0 & 6.7
\end{tabular}




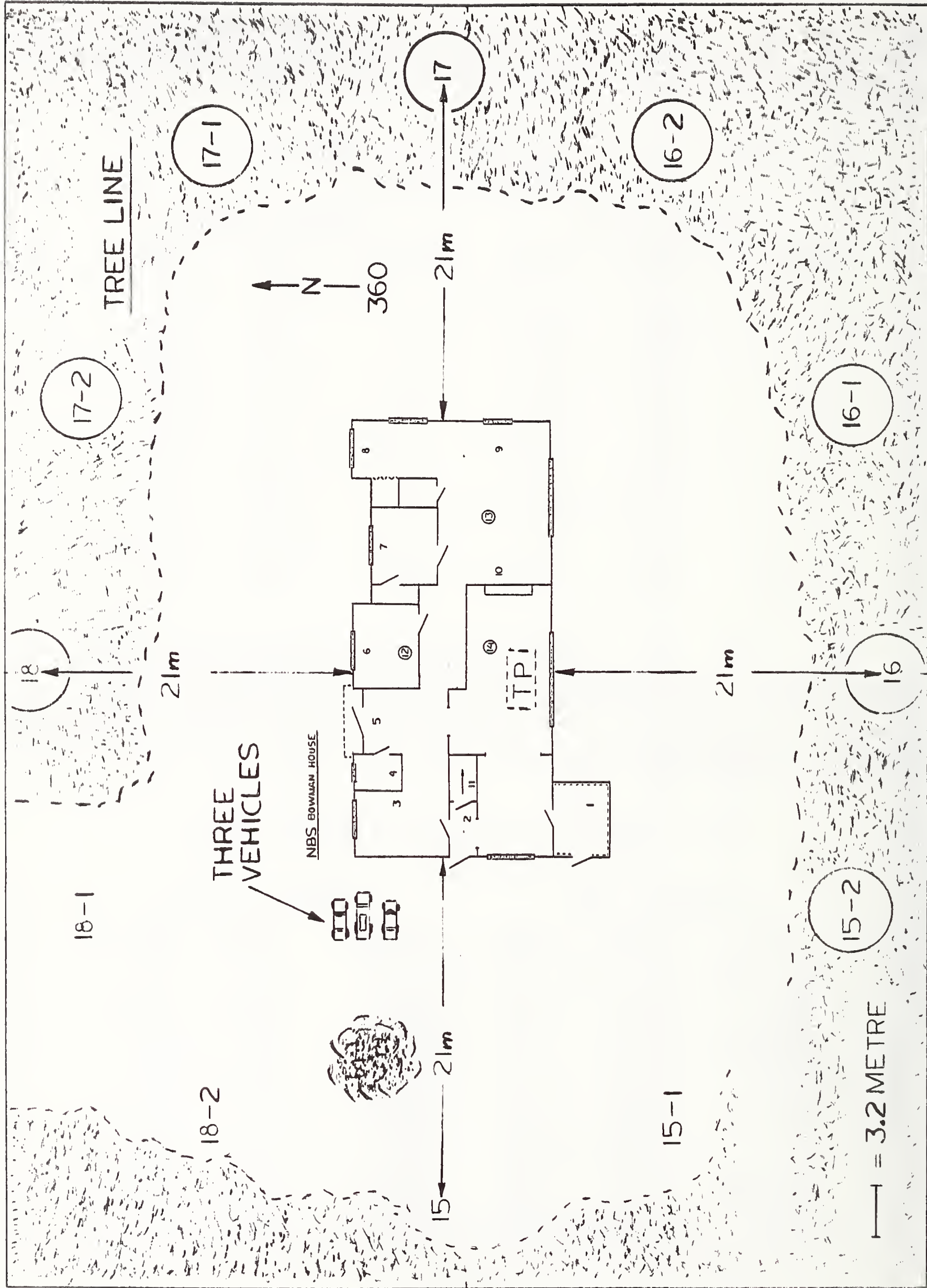


Occasional interference at the level of about $20 \mu \mathrm{N} / \mathrm{m}$ was encountered from the transmitter of the NBS Security Communication system. No impulsive interference was detected. Position 17-2 provided the most attenuated reception point, probably due to the effects of a chain link fence in that vicinity.

The data in table 5, which were obtained through measurements in a corridor of the Metrology Building (see fig. 8), are very similar to that obtained at test location $\mathrm{T} 2$, the main lobby of the Administration Building. In both of these locations, the measured field strength was approximately $0.5 \mathrm{~dB} / \mu \mathrm{V}$ greater than it was at the field test site, for a given radial distance from the transmitter. The reason for this enhanced reception is probably due to the metal walls acting to direct the radiated signal towards the receiving antenna.

Table 5. System 非 1 measurements in the Metrology Building

Transmitter 非251

\begin{tabular}{lll}
\hline Radius & $\mathrm{dB} / \mu \mathrm{V}$ & $\mu \mathrm{V} / \mathrm{m}$ \\
$10 \mathrm{~m}$ & +4.0 & 8.2 \\
$20 \mathrm{~m}$ & +3.5 & 8.0 \\
$30 \mathrm{~m}$ & +3.0 & 7.5 \\
$40 \mathrm{~m}$ & +2.0 & 6.7 \\
$50 \mathrm{~m}$ & +1.5 & 6.4
\end{tabular}

Transmitter 非264

\begin{tabular}{lll}
\hline Radius & $\mathrm{dB} / \mu \mathrm{V}$ & $\mu \mathrm{V} / \mathrm{m}$ \\
$10 \mathrm{~m}$ & +3.5 & 8.0 \\
$20 \mathrm{~m}$ & +3.0 & 7.5 \\
$30 \mathrm{~m}$ & +3.0 & 7.5 \\
$40 \mathrm{~m}$ & +2.0 & 6.7 \\
$50 \mathrm{~m}$ & +2.0 & 6.7
\end{tabular}

\section{Immersion Testing}

For the immersion test a laboratory sink, measuring 40 by 60 by 30 $\mathrm{cm}(16 \times 24 \times 12 \mathrm{in})$ was used. Approximately $50 \mathrm{~L}(13.2 \mathrm{gal})$ of warm water constituted the immersion medium. The measurement antenna was positioned $4 \mathrm{~m}(13.3 \mathrm{ft})$ from the sink.

As can be seen from the data in table 6, an attenuated reception of about $1 \mathrm{~dB} / \mu \mathrm{V}$ (about $11 \%$ reduction in range) occurs during immersion. Both transmitters were apparently unaffected by the brief immersion testing.

Table 6. System 非 immersion tests

\begin{tabular}{|c|c|c|c|c|c|c|}
\hline Reference reading & $4 \mathrm{~m}$ & +4.0 & 8.2 & $4 \mathrm{~m}$ & +3.0 & 7.5 \\
\hline Units immersed for & $4 \mathrm{~m}$ & +3.0 & 7.5 & $4 \mathrm{~m}$ & +2.0 & 6.7 \\
\hline $15 \min (5 \mathrm{~min}$ & $4 \mathrm{~m}$ & +3.0 & 7.5 & $4 \mathrm{~m}$ & +2.0 & 6.7 \\
\hline between readings) & $4 \mathrm{~m}$ & +3.0 & 7.5 & $4 \mathrm{~m}$ & +2.0 & 6.7 \\
\hline Units removed (still wet) & $4 \mathrm{~m}$ & +3.0 & 7.5 & $4 \mathrm{~m}$ & +2.0 & 6.7 \\
\hline Units removed (dry) & $4 \mathrm{~m}$ & +4.0 & 8.2 & $4 \mathrm{~m}$ & +3.0 & 7.5 \\
\hline
\end{tabular}




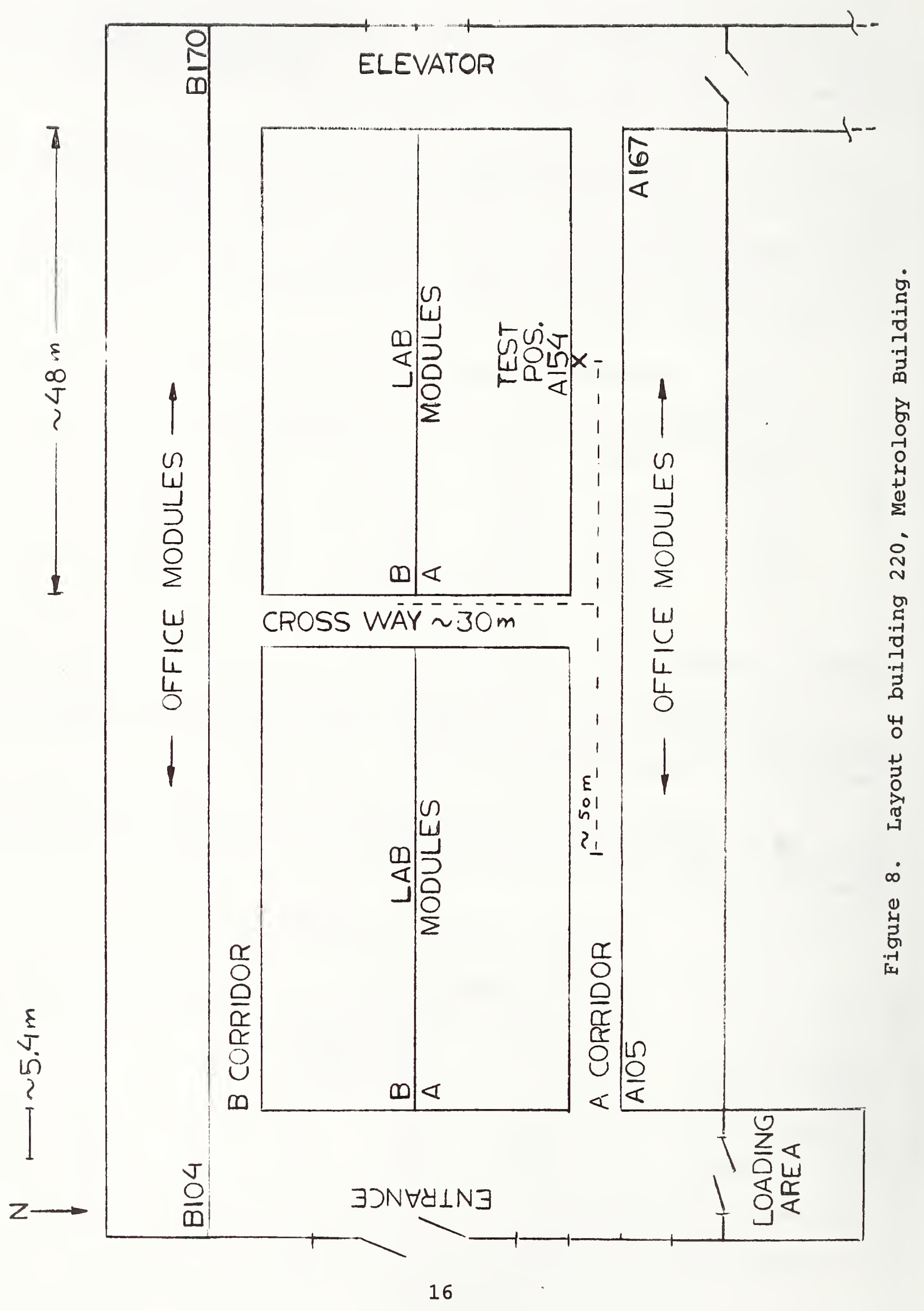


The receiver and interfacing digitizer were used in conjunction with transmitters \#251 and \#264. In general, these units functioned very well and according to the manufacturer's specifications. This monitor has been developed as a telemetry receiver and, as such, is capable of discerning very small signal levels. The manufacturer rates the minimum discernable input signal to be $-150 \mathrm{dBm}$ or $0.0007 \mu \mathrm{V}$. Such a sensitivity is really not required for a parole monitoring system since it would adversely extend the confinement area to be monitored. It is understood, however, that a different design is forthcoming.

The receiving unit converts an incoming radio frequency pulse into an audible tone burst with a frequency of approximately $1000 \mathrm{~Hz}$ which can be monitored with either headphones or with a loudspeaker. The manufacturer uses the $8-\Omega$ audio output as a voltage source for the second unit, the interfacing digitizer (digital processor). Standard phone plugs are used to interconnect both units; however, the phone plug connection was not quite reliable. Intermittent operation was probably due to metal fatigue of the receptacle leaf contacts or oxidation of the plug contacts or the ring and tip. Furthermore, a separate voltage source, one not affected by volume control settings, would be advantageous.

The digital processor converts the tone burst into two different data signals. The received pulse is measured and processed with each received pulse and the data stored until the next pulse. The stored output level is available as a 0 to $1 \mathrm{~mA}$ output for analog recording and is called the amplitude channel. A second channel, the period channel, is used to measure the period between transmitted pulses by counting an internal clock. It also provides a 0 to $1 \mathrm{~mA}$ output. For test purposes, and in order to document the logic and level codes of the unit, the current outputs were converted to a voltage output by means of 100- $\Omega$ precision resistors.

The accompanying photographs, 9A through 9D, show the pulse period and amplitude level functions under operational conditions. The initial turn-on of the monitor is shown in figure 9A. The transmitter was activated beforehand in order to have a signal available as soon as the monitor became functional. The oscilloscope traces shown were taken over a time period of $50 \mathrm{~s}$. The upper trace represents the period signal with an amplitude of $20 \mathrm{mV}$ per division and a scan rate of $5 \mathrm{~s}$ per division. The received pulses, one pulse every $2 \mathrm{~s}$. can be identified as small negative voltage spikes. The small step changes between these pulses are caused by movement of the transmitter. The lower trace shows the amplitude signal; it is used to identify any changes of transmitting or receiving characteristics. As shown in figure 9A, the activation of the monitor takes the form of a multistep change of the amplitude signal, after which an operating level of $1.5 \mathrm{~V}$ is reached indicating normal or "transmitter - in-range" operation. 


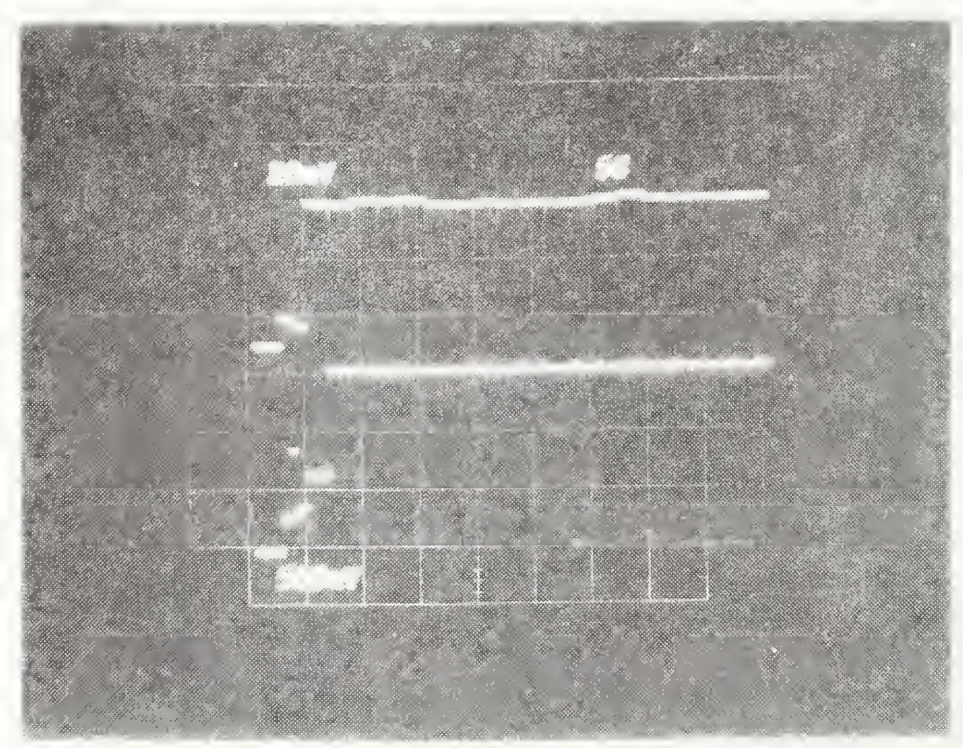

A

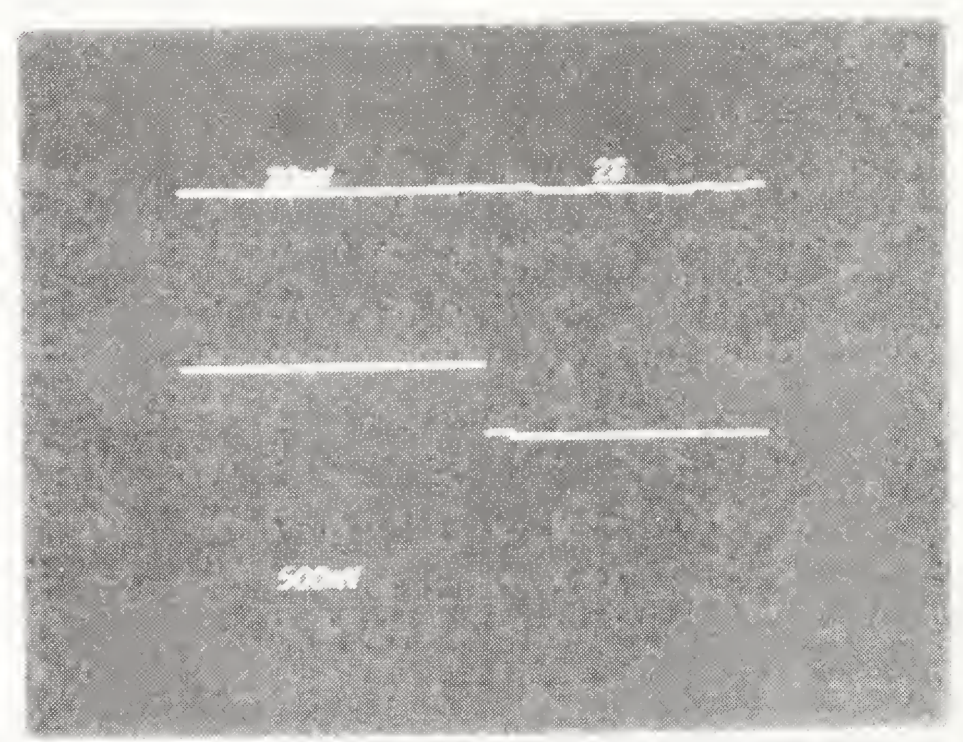

B

Figures $9 \mathrm{~A}$ and $9 \mathrm{~B}$. Pulse period and amplitude level traces under operating conditions. 


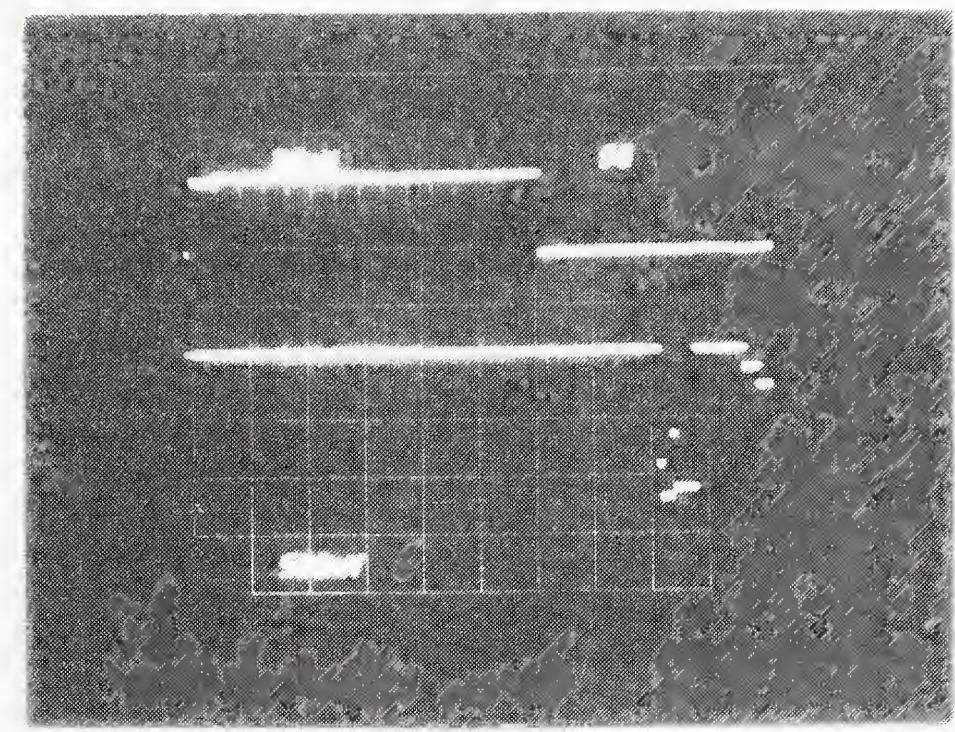

C

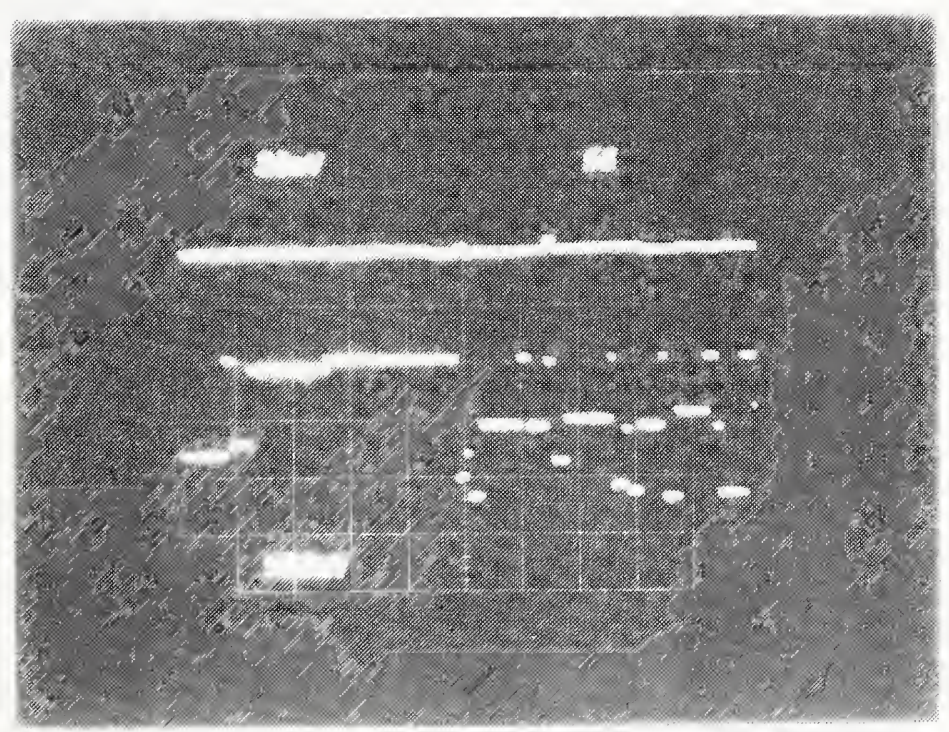

0

Figures 9C and 9D. Pulse period and amplitude level traces under operating conditions. 
In order to show the normally-received pulse train and the period change that occurs when the transmitter is tampered with, figure 9B was obtained using an exposure time of $20 \mathrm{~s}$. The left side of the picture shows the normal signal--one pulse every $2 \mathrm{~s}$. The right half of the picture shows the occurrence of a period change on the upper trace (one pulse every second), indicating that the transmitting loop has been opened. Coinciding with the period change, the amplitude signal on the lower trace steps from approximately $1.5 \mathrm{~V}$ down to a $1-\mathrm{V}$ level, thereby signaling the tamper mode. In figure $9 \mathrm{C}$, the $1-\mathrm{s}$ period pulse train (indicating tamper mode) is still being received, but the transmitter was then turned off near the center of the sweep. After a delay of approximately $10 \mathrm{~s}$, the period signal (upper trace) changes level by about $20 \mathrm{mV}$. This change is indicative of a "no-signal-received" condition. Ten seconds after the level change of the period channel, the amplitude signal changes state and begins to transmit a multistep output code (alarm signal). This continued pulsed output code can be seen in figure 9D. No attempt was made to decode or interpret this transmission.

The next set of pictures, figures $9 \mathrm{E}, 9 \mathrm{~F}$, and $9 \mathrm{G}$ show the radio frequency tone burst from the receiver at the input of the digital processor, the spectral signature of transmitter \#251, and spectral signature of transmitter \#264, respectively.

In figure $9 \mathrm{E}$ a radio frequency tone burst of approximately $20 \mathrm{~ms}$ in duration can be seen. The signal level shown here is about $300 \mathrm{mV}$ peak to peak and was taken from the input of the digital processor. The next picture, figure 9F, shows the spectral position of the emitted signal ( $f \sim 169 \mathrm{MHz}$ ) from transmitter \#251 as well as its magnitude. In figure $9 \mathrm{G}^{\mathrm{C}}$ the signal of transmitter \#264 is shown ( $\mathrm{f}_{\mathrm{q}} 168 \mathrm{MHz}$ ). It can be seen that the emitted signal from this unit is lower than that of transmitter \#251. A probable cause for this difference could be a failing battery. However, this cause was not verified since the sealed case of the transmitter does not allow access to measure the battery voltage. In order to measure the pulsed transmitter output, a specially-designed pickup coil was used in conjunction with the spectrum analyzer. The transmitting/ attachment loop was used to inductively couple the emitted signal to the spectrum analyzer by closing the loop through the center of the coupling coil.

\section{Summary}

System \#1 was tested on the grounds at NBS, Gaithersburg, Maryland, in an open field test site, a high-rise building, a wooden residence, and in a laboratory environment. In general, the system performed as advertised. Range of operation measurements were made out to $50 \mathrm{~m}(164 \mathrm{ft})$ at the field test site indicating use at that range under optimum conditions. At a range of $20 \mathrm{~m}(65.6 \mathrm{ft})$, the field strength measured through the walls of the wooden building was recorded at $2.5 \mathrm{~dB} / \mu \mathrm{V}$, as compared with $3.0 \mathrm{~dB} / \mu \mathrm{V}$ at the field test site, indicating a very small drop in capability. When operated inside the Administration Building, measured field strengths were slightly higher than at the field test site. However, the signal would not penetrate a steel enclosed elevator shaft at a distance of $10 \mathrm{~m}(32.8 \mathrm{ft})$. 


\section{V}
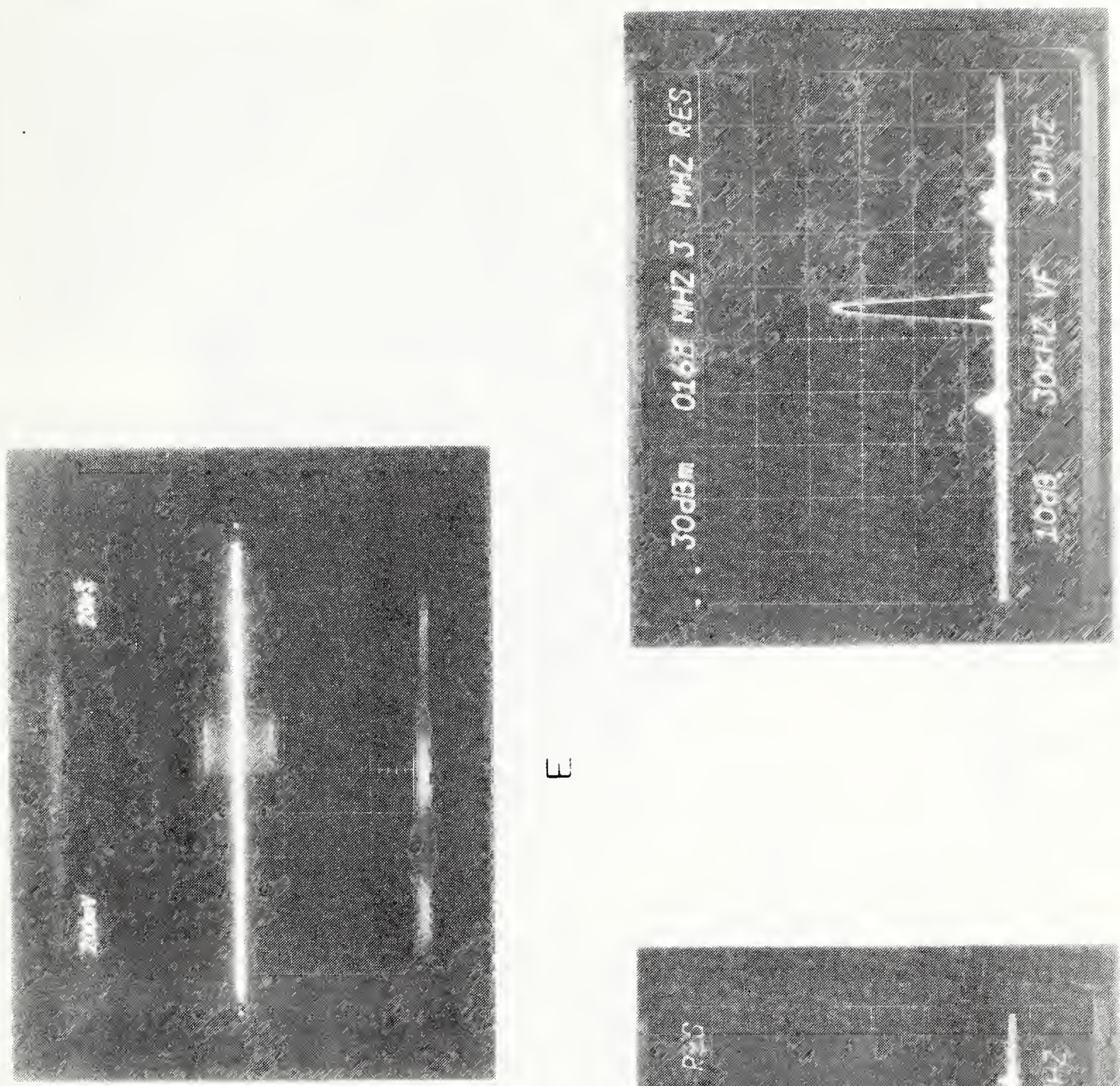

ن

崩

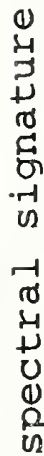

营

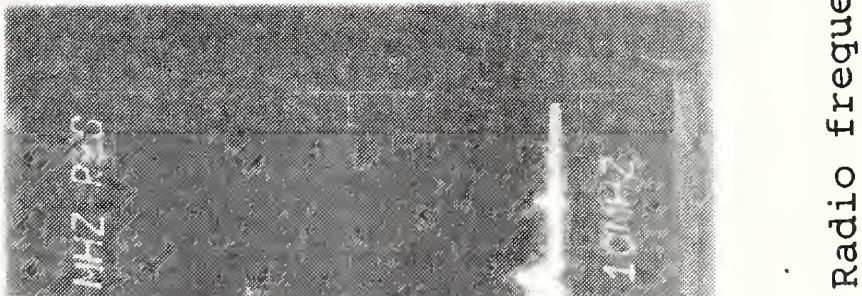

걸

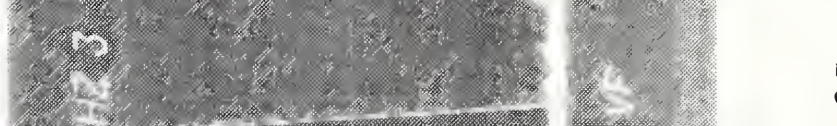

ปั

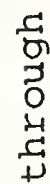

ตู

0
मे
o
-1
-1

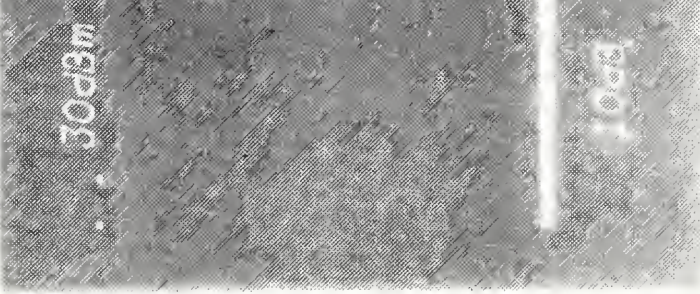


Transmitter effective radiated output power ( 1 pw), based on received signal strength, and supply voltage ( $\sim 3 \mathrm{~V})$ were low enough to be safe under all conceivable usage conditions. Transmitter design does not permit normal access to the electronic circuitry and severance of the transmitting loop automatically transmits a different signal. Radiation from a citizens band radio, walkie-talkies operating at police band frequencies and devices simulating the noise patterns of electric hair dryers, shavers, and mixers did not interfere with the operation of the system. Because the transmitter is hermetically sealed, there was no way of measuring battery current drain without breaking the seal. This system does not send a signal indicating a transmitter or monitor battery low voltage condition. The necklace connections had to be reinforced to handle repeated opening and closing during testing.

The transmitter operated while immersed with a signal attenuation of about $1 \mathrm{~dB} / \mu \mathrm{V}$ at a distance of $4 \mathrm{~m}(13.3 \mathrm{ft})$ from its location. There was no degradation in system performance after removal from the water tank. The monitor portion of the system operates off its own internal 12-V power supply, allowing it to function independently of the household power supply. The transmitters and monitor components were electronically compatible, but the system, as received, was not telephone-line compatible and thus will require additional equipment or redesign to make it function as a complete system.

\section{B. SYSTEM \#2}

The system \#2 equipment consisted of:

1) Transmitter \#1

2) Transmitter \#2

3) Monitor Base Station

4) Digital Telephone Line Tester

5) Telephone Connection Hardware

A photograph of the components for this system is given in figure 10.

The Equipment

1. Transmitters

The transmitter dimensions are shown in figure 11. The casing shown contains the battery power source, transmitter circuitry, and radio frequency (rf) emitting device; the unit is hermetically sealed. Both transmitting units operate at a carrier frequency of $316 \mathrm{MHz}$ and transmit very short rf bursts, approximately 6 ns wide, every 25 s.

The transmitter casing is hermetically sealed to improve its waterproof and tamperproof characteristics. The device is attached to the subject by two straps to either forearm or ankle. However, straps were not submitted for testing. The transmitter cannot be disabled since transmission is continuously on and it has relatively low power consumption. 


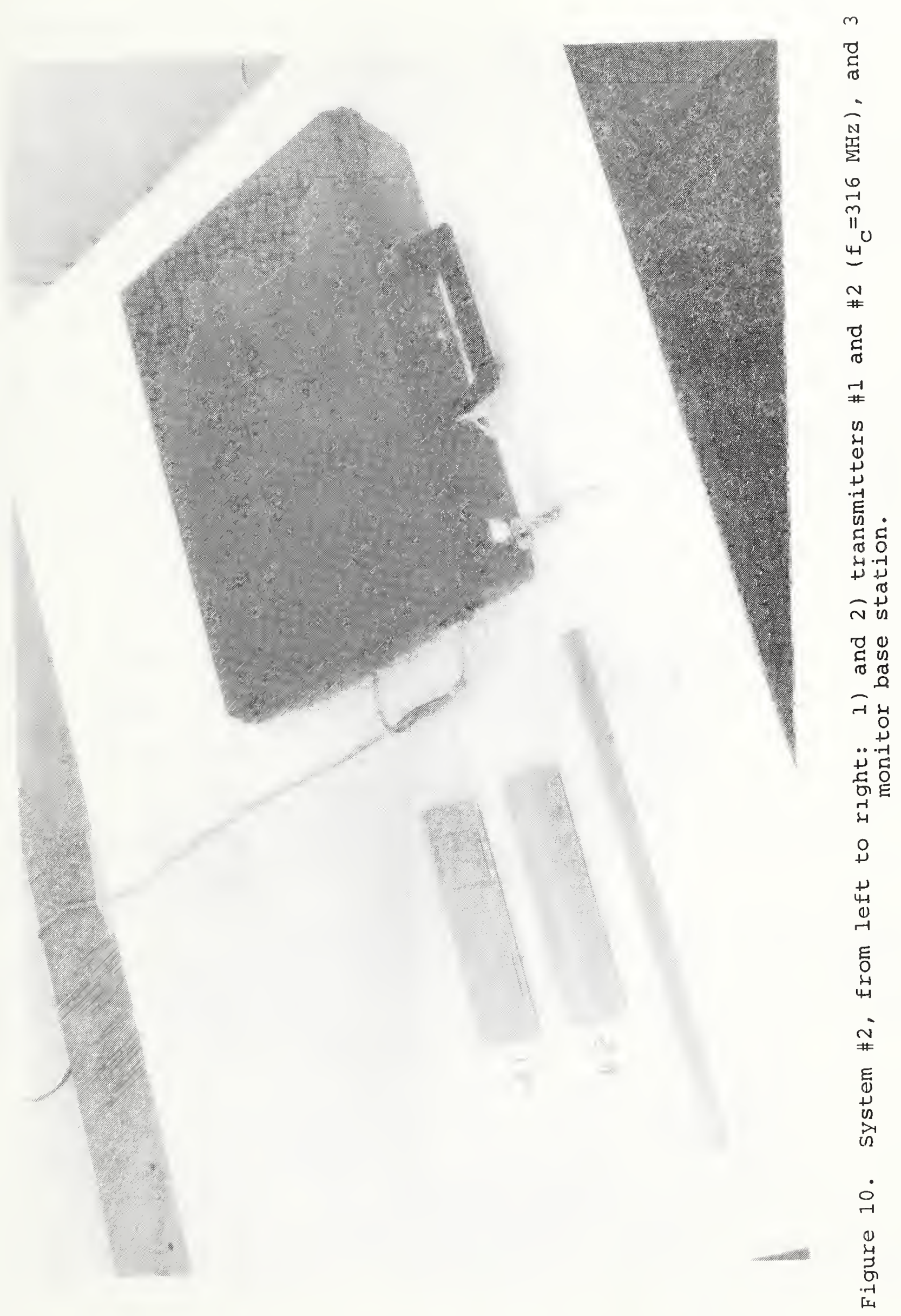



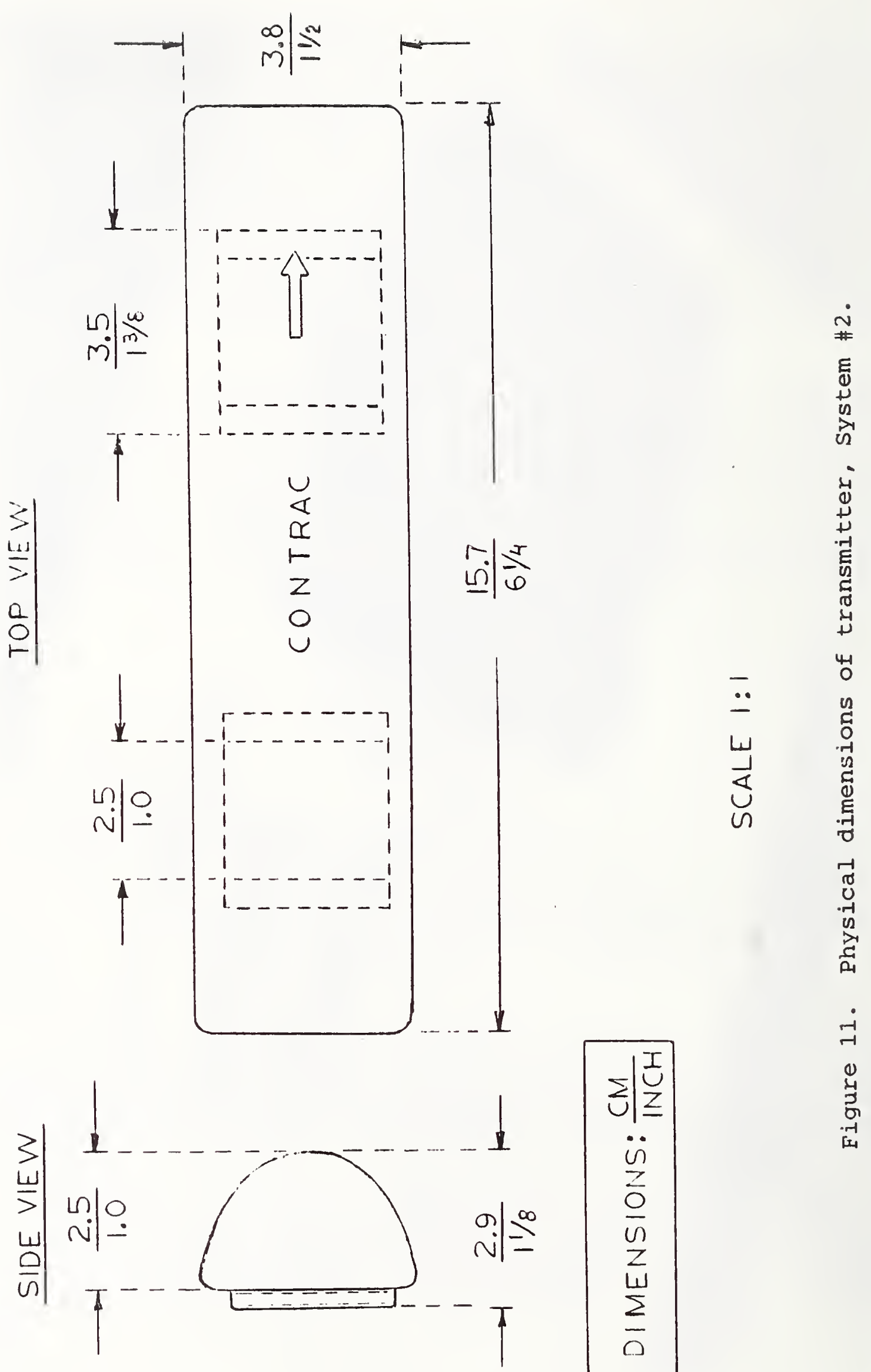
Figure 12 shows the physical dimensions of the home monitor as well as its external features. The areas marked 1 through 4 designate circuit components as they likely have been packaged. Number one probably is a power supply as it is located close to the power switch and the incoming low voltage power line. Position two could contain digital circuits and code storage devices, whereas in area three a dialer and telephone interface could be located. Position four most likely contains the radio frequency transmitter/receiver circuitry. The monitor contents are sealed in a plastic briefcase-size package with an external crimp seal.

\section{Digital Telephone Line Tester}

The digital telephone line tester was used to verify the programmed telephone number and the stored activity code of the monitor, as well as the unit identification digits. The telephone number stored for the autodialer in the monitor electronics was 2729, which is an internal NBS extension number. A unit identification code, in this case code 111, was verified using the digital telephone line tester. The telephone line tester also verifies the following operational codes of the monitor:

$\begin{array}{ll}\text { 1) phone line test: } & 111-3 \\ & 111-3 \\ 111 & -2 \\ 2) & 111-2 \\ & \end{array}$

All codes are indicated in pairs since they are transmitted twice to the host computer for verification.

Transmitter Testing

The following is the performance data using transmitters \#1 and \#2 from tests taken in locations T1 through T4. The field intensity meter and log periodic antenna were used for tests in all four locations. The measurement setups at test sites $\mathrm{T} 1$ through $\mathrm{T} 4$ for testing system \#2 are the same as those for system \#1. The antenna correction factor for the log periodic antenna used in these tests is $17.2 \mathrm{~dB}$.

During these open field tests there was no discernible interference from any adjacent channel communication systems nor was there any impulsive interference that could be detected. The data in table 7A provide a baseline of information about the inherent field strength of the two transmitters as a function of the radial distance from the transmitter. Upon later examination, the data point at $20 \mathrm{~m}$ (65.6 ft) appeared to be anomalous, as a smaller field strength was measured at that location than at locations farther from the monitor. Accordingly, a second set of measurements was taken at a later date to 


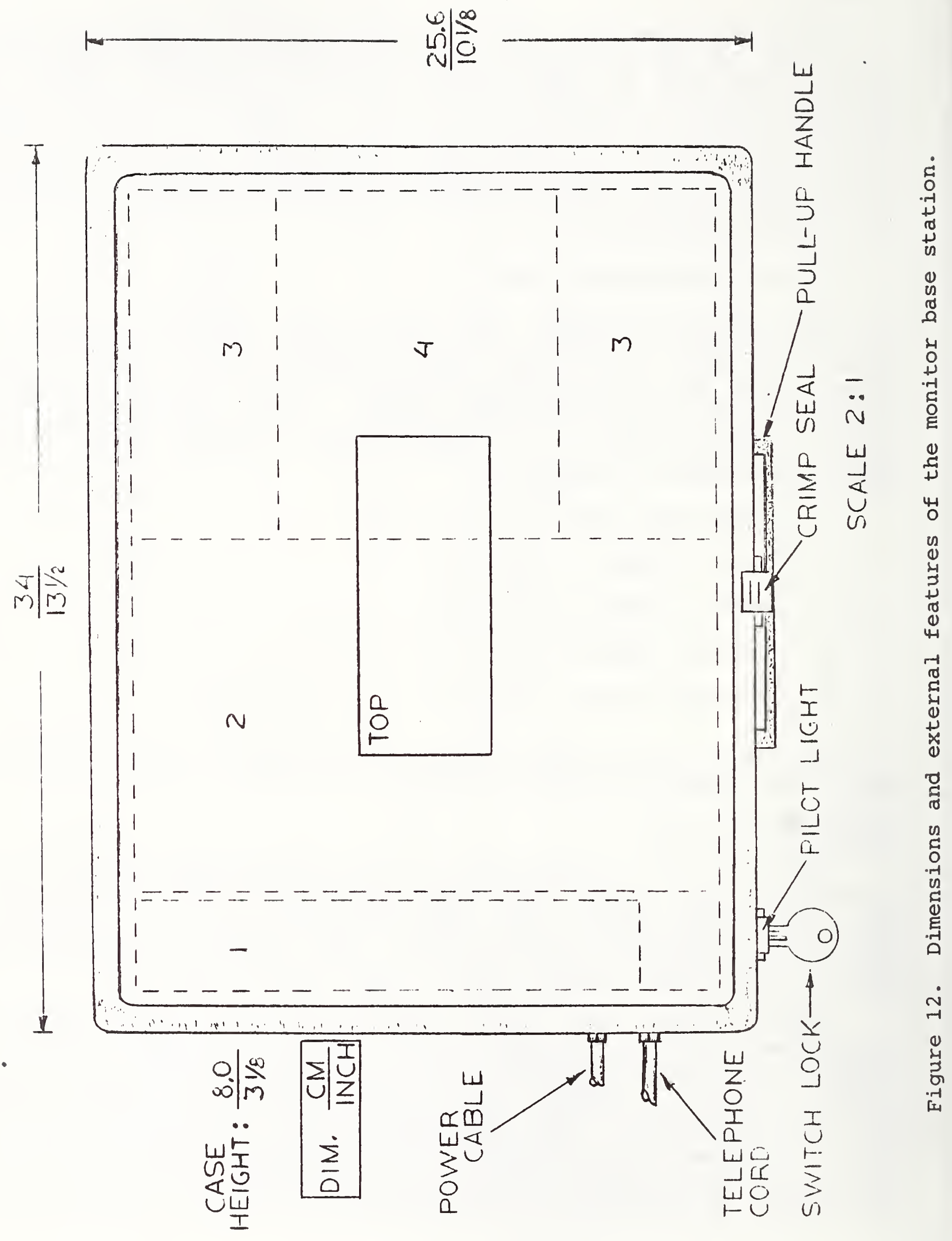


resolve this measurement discrepancy. This second set of measurements, taken only with transmitter \#1 as transmitter \#2 had ceased to operate, verified that the original $20 \mathrm{~m}$ value was incorrect and it should not be treated as a valid data point. See table 7B for these measurement results.

Table 7A. System $\# 2$ measurements at the open field test site

Transmitter \#1

\begin{tabular}{lll}
\hline Radius & $\mathrm{dB} / \mu \mathrm{V}$ & $\mu \mathrm{V} / \mathrm{m}$ \\
$10 \mathrm{~m}$ & +2.0 & 9.1 \\
$20 \mathrm{~m}$ & +1.0 & 8.2 \\
$30 \mathrm{~m}$ & +1.5 & 8.6 \\
$40 \mathrm{~m}$ & +1.5 & 8.6 \\
$50 \mathrm{~m}$ & +1.5 & 8.6
\end{tabular}

Transmitter \#2

\begin{tabular}{lll}
\hline Radius & $\mathrm{dB} / \mu \mathrm{V}$ & $\mu \mathrm{V} / \mathrm{m}$ \\
$10 \mathrm{~m}$ & +2.0 & 9.1 \\
$20 \mathrm{~m}$ & +1.0 & 8.2 \\
$30 \mathrm{~m}$ & +1.5 & 8.6 \\
$40 \mathrm{~m}$ & +1.5 & 8.6 \\
$50 \mathrm{~m}$ & +1.5 & 8.6
\end{tabular}

anvalid data point. See text.

Table 7B. System 非 measurements at the open field test site

Transmitter \#1

\begin{tabular}{lll}
\hline Radius & $\mathrm{dB} / \mu \mathrm{V}$ & $\mu \mathrm{V} / \mathrm{m}$ \\
$10 \mathrm{~m}$ & 1.2 & 8.3 \\
$20 \mathrm{~m}$ & 0.96 & 8.0 \\
$30 \mathrm{~m}$ & 0.8 & 7.9 \\
$40 \mathrm{~m}$ & 0.65 & 7.8 \\
$50 \mathrm{~m}$ & 0.53 & 7.6
\end{tabular}

Tables $8 \mathrm{~A}$ and $8 \mathrm{~B}$ give the measurement results obtained from testing system \#2 in the Administration Building. In this case, table $8 \mathrm{~A}$ gives the data obtained from the straight line measurements and table 8B from the around-the-corner path, as shown in figure 5 . 
Table 8A. System $\# 2$ straight line measurements in the Administration Building

Transmitter 非

\begin{tabular}{lll}
\hline Radius & $\mathrm{dB} / \mu \mathrm{V}$ & $\mu \mathrm{V} / \mathrm{m}$ \\
$10 \mathrm{~m}$ & +1.0 & 8.2 \\
$20 \mathrm{~m}$ & +0.0 & 7.3 \\
$30 \mathrm{~m}$ & +0.0 & 7.3 \\
$40 \mathrm{~m}$ & -1.5 & 6.1 \\
$50 \mathrm{~m}$ & -5.0 & 4.2
\end{tabular}

Transmitter 非2

\begin{tabular}{lll}
\hline Radius & $\mathrm{dB} / \mu \mathrm{V}$ & $\mu \mathrm{V} / \mathrm{m}$ \\
$10 \mathrm{~m}$ & +1.0 & 8.2 \\
$20 \mathrm{~m}$ & +0.0 & 7.3 \\
$30 \mathrm{~m}$ & +0.0 & 7.3 \\
$40 \mathrm{~m}$ & -1.0 & 6.5 \\
$50 \mathrm{~m}$ & -4.0 & 4.6
\end{tabular}

Table 8B. System $\#_{1} 2$ around-the-corner measurements in the Administration Building

Transmitter 非

\begin{tabular}{lcc}
\hline Radius & $\mathrm{dB} / \mu \mathrm{V}$ & $\mu \mathrm{V} / \mathrm{m}$ \\
$10 \mathrm{~m}$ & +1 & 8.2 \\
$20 \mathrm{~m}$ & 0 & 7.3 \\
$30 \mathrm{~m}$ & -2 & 5.7 \\
$40 \mathrm{~m}$ & -4 & 4.6 \\
$50 \mathrm{~m}$ & -6 & 3.6
\end{tabular}

Transmitter 非

\begin{tabular}{lcl}
\hline Radius & $\mathrm{dB} / \mu \mathrm{V}$ & $\mu \mathrm{V} / \mathrm{m}$ \\
$10 \mathrm{~m}$ & +1 & 8.2 \\
$20 \mathrm{~m}$ & 0 & 7.3 \\
$30 \mathrm{~m}$ & -1 & 6.5 \\
$40 \mathrm{~m}$ & -3 & 5.4 \\
$50 \mathrm{~m}$ & -5 & 4.2
\end{tabular}

Reception and measurements at this location showed some signal deterioration, as the reception is progressively lower for a given radial distance from the transmitter, compared to the open field data. Also, normal transmissions made from other levels of the building could not be received. Again, there was a complete loss of signal when the transmitter was in the elevator with the door closed. On a designated corridor level the reception was about the same as given in the table above. The NBS Security Communication System ( $f$ of about $168 \mathrm{MHz}$ ) did not interfere with this system. Also, no impulsive interference was encountered.

During the Bowman House tests, transmitter \#2 became intermittent and ceased to provide reliable measurements. Therefore, no measurement data for this transmitter were recorded. Also, at 8:00 p.m. on July 9, 1985, a strong, pulse-modulated $\mathrm{CW}$ signal interfered with the test. The measured field strength of this signal was $185 \mu \mathrm{V} / \mathrm{m}$. The signal originated from a northeast direction, approximately 30 to 35 degrees relative to the location of NBS. This signal could have originated at the Montgomery County Air Park which is $8.3 \mathrm{~km}$ (5 mi) away at approximately $35^{\circ}$. The data in tables 9 and 10 were obtained when there was no interference from this source. These data show that the reception from this transmitter is fairly uniform from all of the locations throughout the house, and is enhanced (in the order of 1 $\mathrm{dB} / \mu \mathrm{V}$ ) over that obtained in the open field. 
Table 9. System 非 measurements at the Bowman House

(inside locations 1 through 14)

Transmitter 非 1

\begin{tabular}{cccccc}
\hline Location & $\mathrm{dB} / \mu \mathrm{V}$ & $\mu \mathrm{V} / \mathrm{m}$ & Location & $\mathrm{dB} / \mu \mathrm{V}$ & $\mu \mathrm{V} / \mathrm{m}$ \\
\cline { 5 - 7 } 1 & +2.0 & 9.1 & 8 & +1.5 & 8.6 \\
2 & +2.0 & 9.1 & 9 & +1.5 & 8.6 \\
3 & +2.0 & 9.1 & 10 & +2.0 & 9.1 \\
4 & +1.5 & 8.6 & 11 & +2.0 & 9.1 \\
5 & +2.0 & 9.1 & $\underline{12}$ & +2.0 & 9.1 \\
6 & +2.0 & 9.1 & $\underline{13}$ & +2.0 & 9.1 \\
7 & +2.0 & 9.1 & $\underline{14}$ & +2.0 & 9.1
\end{tabular}

Table 10. System $\# 2$ measurements at the Bowman House (outdoor locations 15 through 18)

Transmitter 非 1

\begin{tabular}{lll}
\hline Location & $\mathrm{dB} / \mu \mathrm{V}$ & $\mu \mathrm{V} / \mathrm{m}$ \\
& & \\
West 15 & +2.0 & 9.1 \\
$15-1$ & +2.0 & 9.1 \\
$15-2$ & +2.0 & 9.1 \\
South 16 & +2.5 & 9.7 \\
$16-1$ & +2.5 & 9.7 \\
$16-2$ & +1.5 & 8.6
\end{tabular}

Transmitter 非

\begin{tabular}{lll}
\hline Location & $\mathrm{dB} / \mu \mathrm{V}$ & $\mu \mathrm{V} / \mathrm{m}$ \\
& & \\
East 17 & +2.5 & 9.7 \\
$17-1$ & +2.5 & 9.7 \\
$17-2$ & +2.5 & 9.7 \\
North 18 & +2.0 & 9.1 \\
$18-1$ & +2.0 & 9.1 \\
$18-2$ & +2.0 & 9.1
\end{tabular}

Table 11 gives the results of tests conducted in an all-metal environment as the corridor walls consist of forged sheet metal. No interference of any kind was detected during this test. At this frequency, the data obtained in this location are very similar to the open field test data, indicating that the all-metal environment did not particularly enhance the reception for this type of transmitter.

Table 11. System 非 measurements in the Metrology Building

Transmitter \#1

\begin{tabular}{lll}
\hline Radius & $\mathrm{dB} / \mu \mathrm{V}$ & $\mu \mathrm{V} / \mathrm{m}$ \\
$10 \mathrm{~m}$ & +2.0 & 9.1 \\
$20 \mathrm{~m}$ & +1.5 & 8.6 \\
$30 \mathrm{~m}$ & +1.5 & 8.6 \\
$40 \mathrm{~m}$ & +1.5 & 8.6 \\
$50 \mathrm{~m}$ & +1.0 & 8.0
\end{tabular}


Table 12 gives the results for immersion testing of system \#2. The test setup was identical to that used to test system \#1 and no radio frequency or impulsive interference was detected during this test.

Table 12. System 非2 immersion tests

Transmitter 非 1

\begin{tabular}{llll}
\hline Remarks & Radius & $\mathrm{dB} / \mu \mathrm{V}$ & $\mu \mathrm{V} / \mathrm{m}$ \\
Reference reading & $4 \mathrm{~m}$ & +2.0 & 9.1 \\
Unit immersed for 15 min & $4 \mathrm{~m}$ & -4.0 & 4.6 \\
(5 min between readings) & $4 \mathrm{~m}$ & -4.0 & 4.6 \\
& $4 \mathrm{~m}$ & -4.0 & 4.6. \\
Unit removed (still wet) & $4 \mathrm{~m}$ & -1.0 & 6.5 \\
Unit removed (dry) & $4 \mathrm{~m}$ & +2.0 & 9.1
\end{tabular}

Considerable attenuation (about $6 \mathrm{~dB} / \mu \mathrm{V}$ ) occurs for this transmitter under the immersion testing conditions used. Also, there is about a $3 \mathrm{~dB} / \mu \mathrm{V}$ attenuated reception (about $29 \%$ reduction in range) of the transmitted signal when the surface of the transmitter is wet. once dry, the transmitter was apparently unaffected by the brief immersion testing.

\section{Monitor Testing}

The photograph of figure 13 shows the monitor and transmitters with the monitor interfaced to the telephone system. Once the monitor base station is connected to the telephone line and is turned on (activated), it performs automatically. In order to document its functions, such as line seizure, dialing, etc., an oscilloscope with a Polaroid camera attachment was connected to the telephone line. In order to photograph the trace perturbations, elapsed time exposure had to be used. The exposure time for figures 14A through 14D varied from 10 to $50 \mathrm{~s}$ or 1 to $5 \mathrm{~s}$ per division. Figure $14 \mathrm{~A}$ shows the monitor base station telephone line output at a zero volt level (initial state). Upon turn-on, a level change occurs after approximately 1.7 seconds. This operational level is about $52 \mathrm{~V}$ peak and is held high for approximately $10 \mathrm{~s}$ after which line seizure occurs (see fig. 14B). Note that the voltage level reduces to about $12 \mathrm{~V}$.

In figure $14 \mathrm{~B}$ the automatic dialing process can be seen in detail. Following the previously set $12-\mathrm{V}$ level, a short zero level can be seen; it is followed by another level change up to about $20 \mathrm{~V}$. Approximately $1.5 \mathrm{~s}$ after this change the dial pulse train appears. The number 2729, an NBS extension number, can be recognized by counting pulses. The next picture, figure $14 \mathrm{C}$, shows a second identical dial sequence followed by a 3 -s end-of-message pulse (zero level). All codes dialed are paired or transmitted twice for host computer 


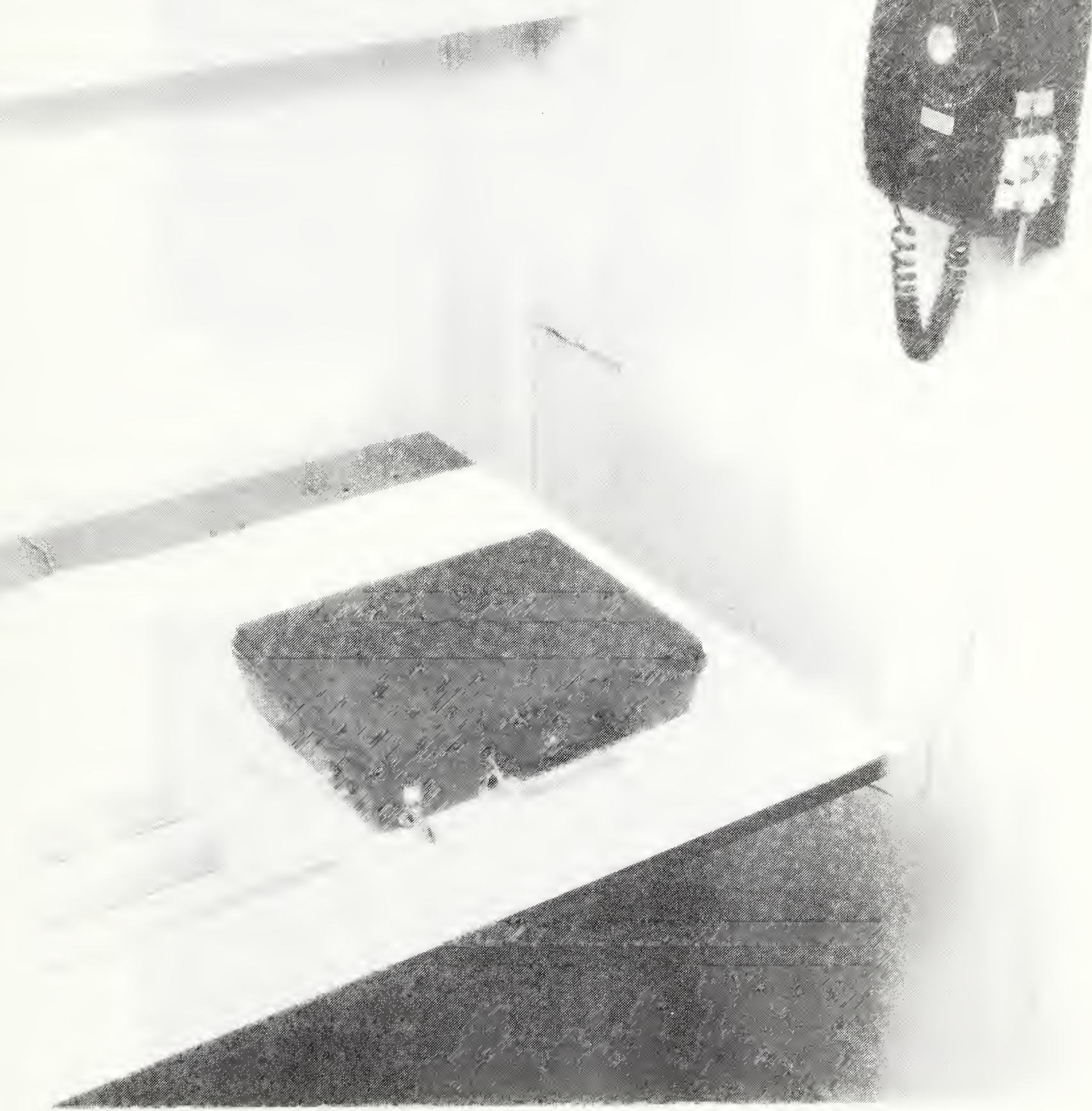

Figure 13. Monitor base station connected to the telephone line. 


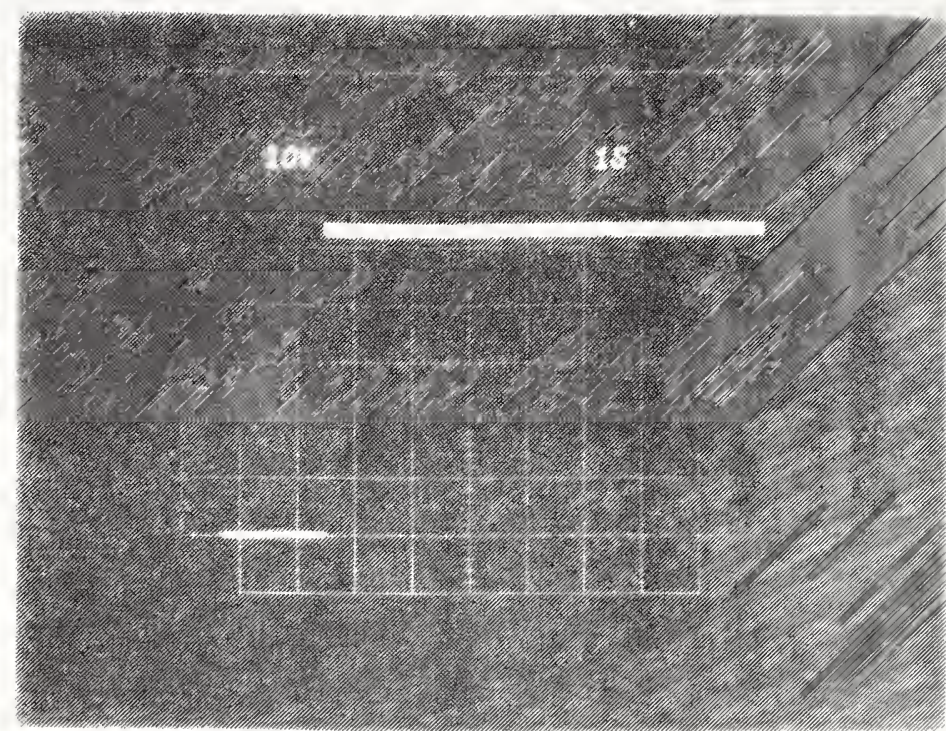

A

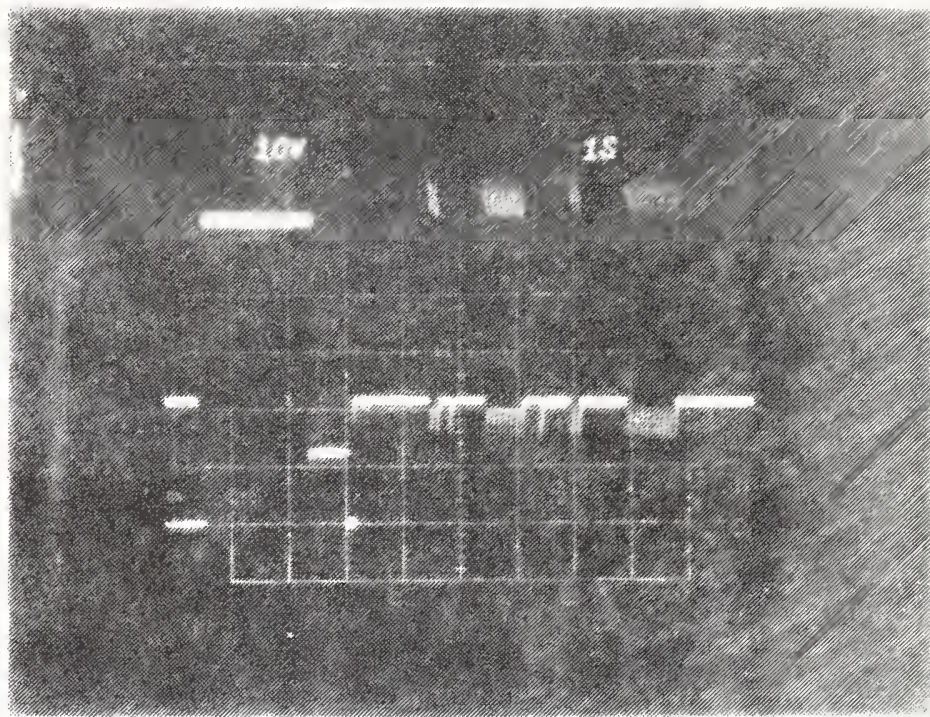

B

Figures $14 \mathrm{~A}$ and $14 \mathrm{~B}$. Telephone line operational levels and dialing pulse trains. 


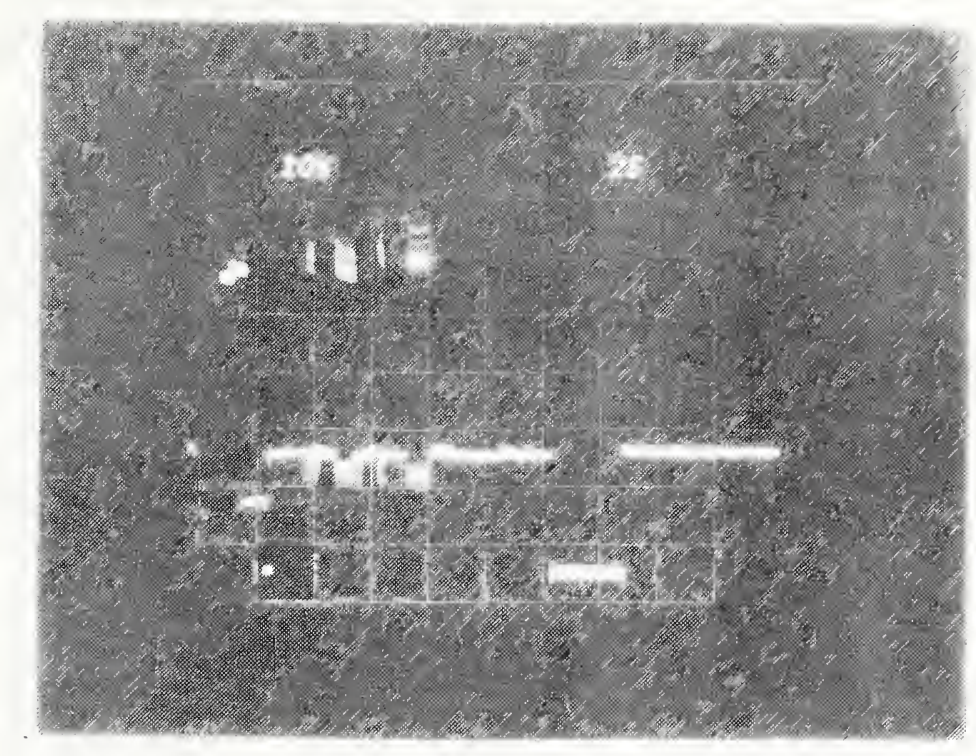

C

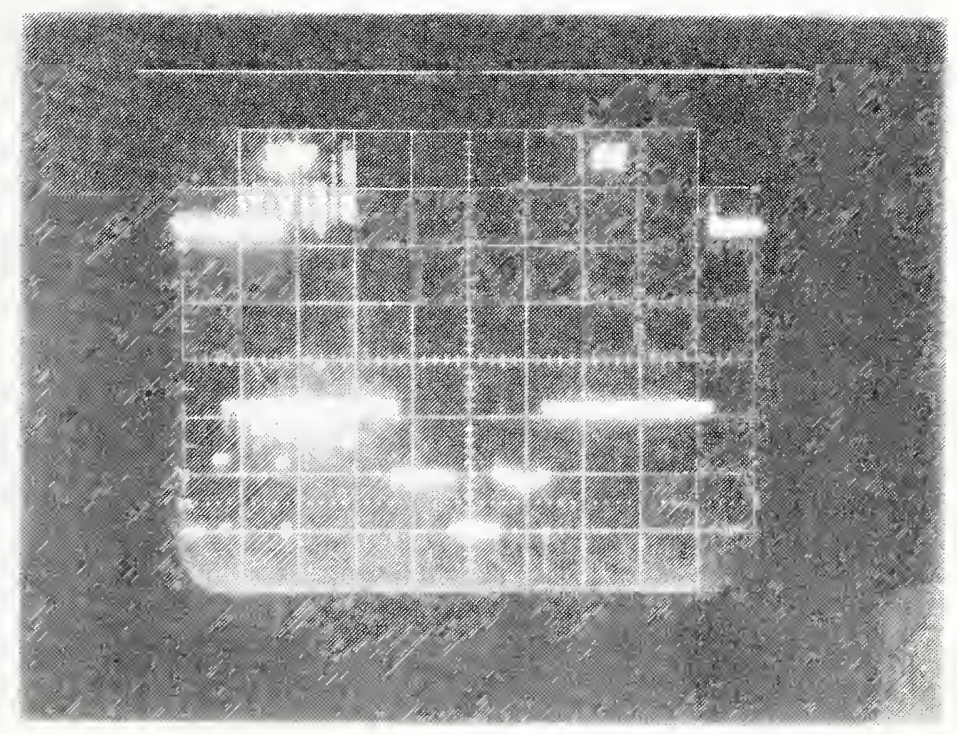

し

Figures $14 \mathrm{C}$ and 14D. Telephone line operational levels and dialing pulse trains. 
verification. Note that figure $14 \mathrm{C}$ has a $2-s$ per division time scale. The following picture, figure 14D, is a 50-s time exposure and shows that after check-in dialing, the telephone was in use for almost $14 \mathrm{~s}$, indicated here by a $10-\mathrm{V}$ level. As the receiver was returned to the cradle, the dc level changed to $20 \mathrm{~V}$. Fifteen seconds later the level changed back to the $52-\mathrm{V}$ operational level.

In order to show the transmitted pulses of transmitters \#1 and \#2, a spectrum analyzer with a frequency range from $1 \mathrm{kHz}$ to $1.8 \mathrm{GHz}$ was used in conjunction with a specially-constructed pickup coil. This coil has five turns of \#13-gage copper wire; it is connected in series to a 50- $\Omega$ resistor and connects directly to the spectrum analyzer's $50-\Omega$ input. The coil diameter is about $5 \mathrm{~cm}$ ( 2 in) and permits insertion of the receiver in order to inductively couple the received signal to the input of the spectrum analyzer. Using this setup provided the photograph of figure 14E, the emitted pulse from transmitter \#1 and its spectral position of f $\sim 321 \mathrm{MHz}$. Similarly, figure 14F, shows the emitted signal from transmitter \#2 at f $\sim 317 \mathrm{MHz}$. One additional picture, figure 14G, shows a signal at about $302 \mathrm{MHz}$ that was received whenever the home monitor station was activated. The distance between home monitor and the pickup coil of the spectrum analyzer was approximately $2.5 \mathrm{~m}(8.3 \mathrm{ft})$. The meaning of this signal is not quite clear; however, it could be interpreted either as undesired radiation from the local oscillator or, perhaps, as radiation from a built-in feature used to control the lid tamper mode.

$\underline{\text { Summary }}$

System \#2 was tested on the grounds at NBS, Gaithersburg, MD, in an open field test site, a high-rise building, a wooden residence and in a laboratory environment. In general, the system performed as advertised. Range of operation measurements were made out to $50 \mathrm{~m}$ (164 ft) at the field test site, indicating use at that range under optimum conditions. Measured field strengths inside the Administration Building were substantially less than those measured at the field test site. However, field strengths measured through the walls of the wooden building were similar to those originally measured at the open field test site.

Effective radiated output power ( $1 \mathrm{pw})$, based on measured field strength, and supply voltage $(\sim 9 \mathrm{~V})$ were low enough to be safe under all conceivable usage conditions. The low transmitter duty cycle, one short pulse every $25 \mathrm{~s}$, also reduces the risk of injury to the wearer. This transmitter has no "tamper" signal and the design of the case does not allow normal access to the electronic circuitry or power supply, and it has no protruding antenna. Placing a hand on the receiver/monitor produced a "tamper" signal, as advertised. Radiation from a citizens band radio, walkie-talkies operating at police band frequencies, and devices simulating the noise patterns of electric hair dryers, shavers, and mixers did not interfere with the operation of the system. Because of the sealed case, there was no way to measure transmitter battery current drain. The transmitter operated while immersed with a signal attenuation of about $6 \mathrm{~dB}$ at a distance of $4 \mathrm{~m}$ $(13.3 \mathrm{ft})$ from its location and there was no degradation in system performance after removal from the water tank and dried. 

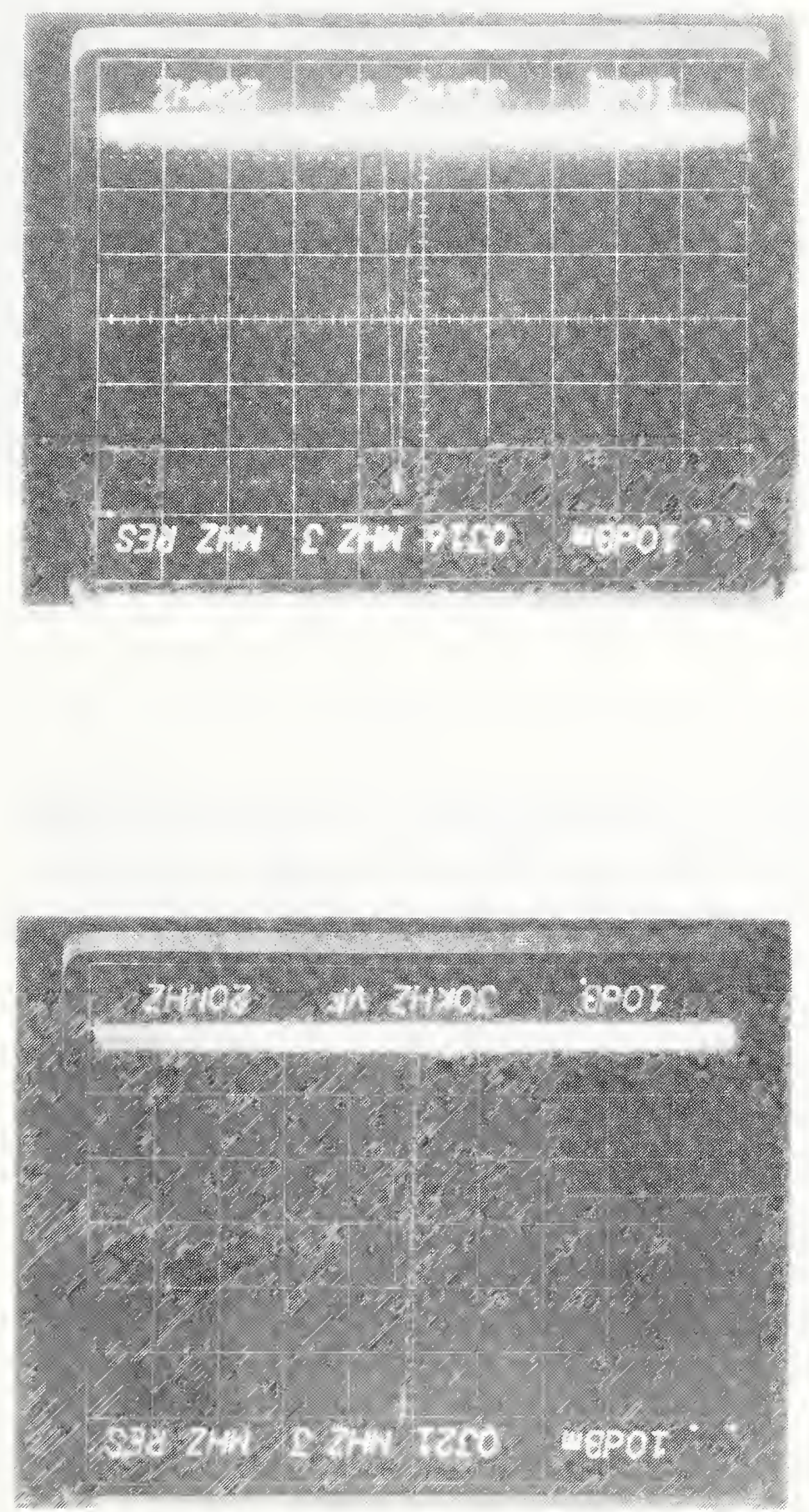

Figures $14 \mathrm{E}$ and $14 \mathrm{~F}$. Spectral signatures of transmitters. 


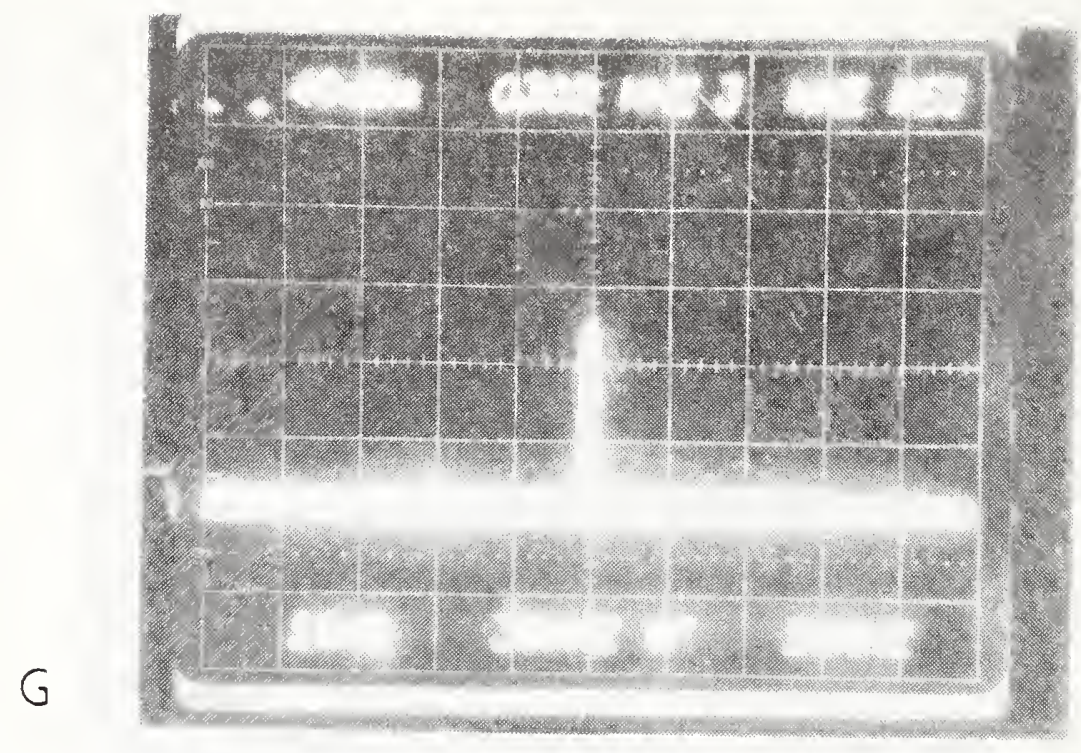

Figure 14G. Spectral signature of monitor base station emission.

The monitor uses standard household power for normal operations. If household power is lost, an internal 12-V battery provides standby power for an estimated $10 \mathrm{~h}$ of operation. Notice of impending loss of power is transmitted automatically when the battery voltage level drops to $11.5 \mathrm{~V}$. The transmitter and monitor components were electronically compatible, and system is telephone line compatible as it meets the requirements for impedance, pulse rate, and transmission level. Pulse dialing systems, although compatible with both rotary and touch-tone dialing systems, are not as fast acting as touch-tone systems.

\section{DESCRIPTION AND EVALUATION - 1986 TESTS}

The two systems received in 1986 were tested in the exact same locations as those in 1985 with the exception of test site \#2, the Administration Building. The results obtained from testing in the Metrology Building, which also has metal walls, were similar enough to permit the elimination of tests at site \#2. As requested by the sponsor, a substantial number of measurements were made with the transmitter worn at the ankle to better simulate the actual human/transmitter daily environment. Also, measurements were made with the wearer's body directly between the transmitter and the receiver, again to better simulate actual using conditions. These are the major differences between the 1985 tests and the 1986 tests.

The test equipment used in the 1985 tests was again utilized, so its description will not be repeated in this section of the report. The same rationale will be applied to the functioning of the transmitters and receiver/monitors. Systems 3 and 4 were designed to work in the same general manner as the other two, so there is no need to describe their operation herein. 
Field strength measurements reported on in the tables for systems 3 and 4 are given only in one value, decibels referenced to a microvolt $(\mathrm{dB} / \mu \mathrm{V})$. Conversion of these values to field strengths in microvolts per meter can be easily done by those who desire it.

\section{A. SYSTEM \#3}

Two transmitters and a receiver/monitor were received from the manufacturer for these tests. System \#3 operated at a frequency of approximately $323 \mathrm{MHz}$ as illustrated in figure 15, which shows the spectral characteristics of the transmitted signal. For this system the rf bursts occurred at approximately 58-s intervals. The transmitters for this system appeared to have much greater output power than those tested the previous year. This resulted in substantially greater operational range measurements. The first pair of system \#3 transmitters failed and had to be replaced before testing could begin. Later, one of the replacement transmitters ceased to operate part way through the testing, and the Bowman House and immersion tests were conducted using only one test unit. It is the opinion of test personnel that the results would have been similar if the second transmitter had been available for these two tests. Although these units were not dismantled, it is assumed that the inability to transmit was due to an internal power supply or component failure.

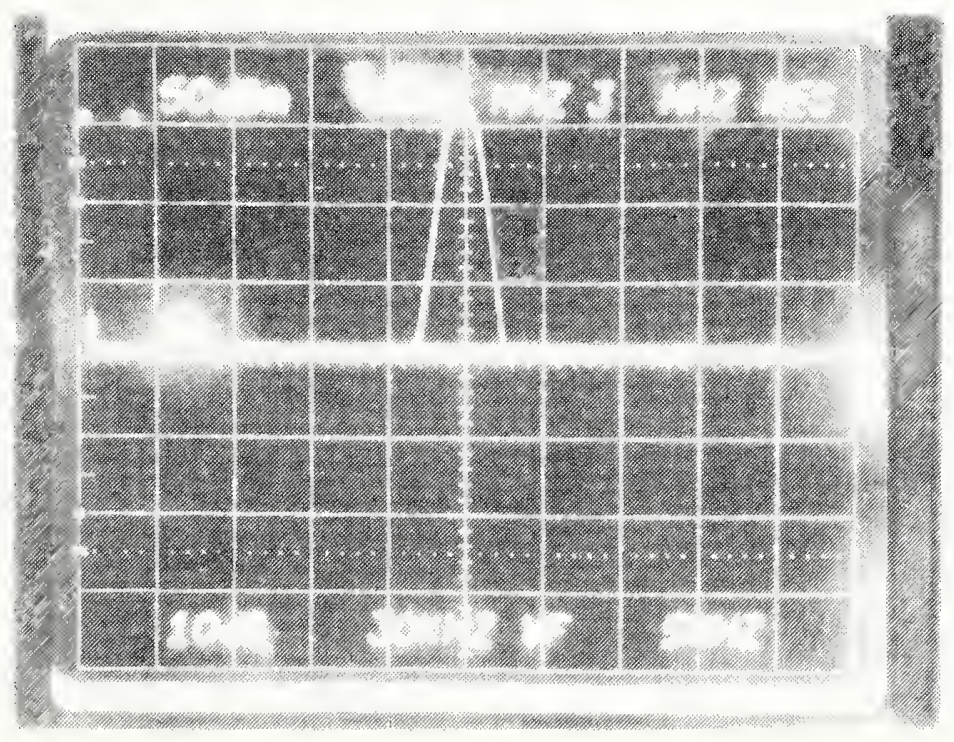

Figure 15. Transmitter spectral signature for system \#3.

\section{Summary}

System \#3 was tested on the grounds at the National Bureau of Standards (an open field test site), in a wooden residence, in a building with metal walls, and in a laboratory environment. In general, the system performed in accordance with the manufacturers specifications. As shown in table 13, range of operation measurements 
were made out to $75 \mathrm{~m}$ (246 ft) with one of the transmitters at the open field test site indicating satisfactory use at that range under line-of-site conditions. Measurements were taken at the 4 ft high positions, front and back, and with the transmitter worn on the ankle. The front and ankle positions produced almost identical readings out to a distance of $55 \mathrm{~m}(180.4 \mathrm{ft})$, with about a $6 \mathrm{~dB} / \mu \mathrm{V}$ reduction in signal strength occurring when measurements were made with the transmitter in the back position.

Table 13. System 非 3 measurements at the open field test site

Transmitter 非3

\begin{tabular}{cccc}
\hline & \multicolumn{3}{c}{ Location } \\
\cline { 2 - 4 } $\begin{array}{c}\text { Distance } \\
\text { (in } \mathrm{m})\end{array}$ & $\begin{array}{l}\text { Front } \\
\text { (Field }\end{array}$ & $\begin{array}{r}\text { Back } \\
\text { strength }\end{array}$ & $\begin{array}{r}\text { Ankle } \\
\mathrm{dB} / \mu \mathrm{V})\end{array}$ \\
10 & 35 & 30 & 35 \\
20 & 32 & 26 & 32 \\
30 & 24 & 22 & 24 \\
40 & 21 & 13 & 21 \\
50 & 18 & 11 & 18 \\
55 & 16 & 10 & 16
\end{tabular}

Transmitter 非

\begin{tabular}{cccc}
\hline & \multicolumn{3}{c}{ Location } \\
\cline { 2 - 4 } Distance & $\begin{array}{l}\text { Front } \\
\text { (in m) }\end{array}$ & $\begin{array}{c}\text { Back } \\
\text { (Field }\end{array}$ & $\begin{array}{c}\text { Ankle } \\
\text { strength }\end{array}$ \\
& & & \\
10 & 42 & 38 & 42 \\
20 & 36 & 31 & 36 \\
30 & 31 & 26 & 29 \\
40 & 27 & 19 & 26 \\
50 & 21 & 16 & 20 \\
55 & 18 & 13 & 18 \\
75 & 4 & - & -
\end{tabular}

At a range of $20 \mathrm{~m}$ (65.6 ft), the field strengths measured through the walls of the wooden building were 48-50 dB/ $\mu \mathrm{V}$, as compared with 32 $\mathrm{dB} / \mu \mathrm{V}$ at the open field test site, again demonstrating the ability of transmissions at this frequency band to penetrate glass and wooden structures. The difference in ground moisture content and terrain irregularities near the building undoubtedly contributed to this difference in received signal strength which is illustrated in table 14. Ankle measurements were again very similar to those taken at the front position, and there was a $5 \mathrm{~dB} / \mu \mathrm{V}$ reduction in signal strength when the wearer's body was between the transmitter and the receiver. 
Table 14. System \#3 measurements at the Bowman House

Transmitter 非3

\begin{tabular}{l}
\hline Location $\quad$ Field strength \\
$($ in $\mathrm{dB} / \mu \mathrm{V})$
\end{tabular}

1

2

3

4

5

6

7

8

9

10

11

$\frac{12}{13}$

$\underline{14}$

\section{5}

46

46

48

48

48

48

48

48

48

48

14

$-$

48
Transmitter 非 3

\begin{tabular}{lc}
\hline Location & $\begin{array}{c}\text { Field strength } \\
(\text { in } \mathrm{dB} / \mu \mathrm{V})\end{array}$
\end{tabular}

15
$15-1$
$15-2$
16
$16 \mathrm{~B} / \mathrm{A}$
$16-1$
$16-2$
17
$17-1$
$17-2$
18
$18 \mathrm{~B} / \mathrm{A}$
$18-1$
$18-2$

48

49

49

50

$45 / 49$

49

50

50

49

49

50

$45 / 49$

49

48

12 - Underlined numbers are basement locations

$\overline{15}$ thru 18-2 - Outside locations

$16 \mathrm{~B} / \mathrm{A}, 18 \mathrm{~B} / \mathrm{A}$ - Back and ankle measurements

As shown in table 15, measurements inside the metal building (see fig. 8) produced a signal strength of $44 \mathrm{~dB} / \mu \mathrm{V}$ at $20 \mathrm{~m}(65.6 \mathrm{ft})$, probably due to reflections from the walls and operation in $a$ climate-controlled environment. The reader should note the reduced field strength levels for the cross corridor measurements.

Table 15. System \#3 measurements in the Metrology Building

Transmitter \#3

\begin{tabular}{cccc}
\hline & \multicolumn{3}{c}{ Location } \\
\cline { 2 - 4 } $\begin{array}{c}\text { Distance } \\
\text { (in } \mathrm{m} \text { ) }\end{array}$ & $\begin{array}{l}\text { Front } \\
\text { (Field }\end{array}$ & $\begin{array}{r}\text { Back } \\
\text { strength }\end{array}$ & $\begin{array}{r}\text { Ankle } \\
\text { (FB/ } \mathrm{\mu V} \text { ) }\end{array}$ \\
10 & 48 & 42 & 48 \\
20 & 44 & 40 & 44 \\
30 & 41 & 37 & 40 \\
40 & 39 & 33 & 38 \\
50 & 35 & 30 & 34
\end{tabular}

Cross Corridor $5 \mathrm{~m} 35 \mathrm{~dB} / \mu \mathrm{V}$ $10 \mathrm{~m} 30 \mathrm{~dB} / \mu \mathrm{V}$
Transmitter 非

\begin{tabular}{cccc}
\hline & \multicolumn{3}{c}{ Location } \\
\cline { 2 - 4 } $\begin{array}{c}\text { Distance } \\
\text { (in m) }\end{array}$ & $\begin{array}{l}\text { Front } \\
\text { (Field }\end{array}$ & $\begin{array}{c}\text { Back } \\
\text { strength }\end{array}$ & $\begin{array}{c}\text { Ankle } \\
\mathrm{dB} / \mu \mathrm{V} \text { ) }\end{array}$ \\
10 & 50 & 45 & 50 \\
20 & 47 & 40 & 43 \\
30 & 43 & 38 & 40 \\
40 & 41 & 36 & 39 \\
50 & 39 & 33 & 36
\end{tabular}

Cross Corridor $5 \mathrm{~m} 37 \mathrm{~dB} / \mu \mathrm{V}$ $10 \mathrm{~m} 32 \mathrm{~dB} / \mu \mathrm{V}$

The transmitter operated while immersed with a maximum signal attenuation during the 15-min period of $6 \mathrm{~dB} / \mu \mathrm{V}$, which was expected at this frequency band (see table 16). It returned to normal operation 
after removal from the water tank. Radiation from household devices did not interfere with the operation of this system and, in keeping with its design, it does not send a signal when tampered with.

Table 16. System 非 immersion tests

Transmitter \#3

\begin{tabular}{|c|c|c|}
\hline & $\begin{array}{l}\text { Distance } \\
\text { (in } \mathrm{m})\end{array}$ & $\begin{array}{l}\text { Field strength } \\
(\text { in } \mathrm{dB} / \mu \mathrm{V})\end{array}$ \\
\hline Reference & 4 & 62 \\
\hline $\begin{array}{l}\text { Unit immersed } \\
\text { for } 15 \mathrm{~min} \text { ( } 5 \mathrm{~min} \\
\text { between readings) }\end{array}$ & 4 & $\begin{array}{l}55 \\
57 \\
58\end{array}$ \\
\hline $\begin{array}{l}\text { Unit removed } \\
\text { (still wet) }\end{array}$ & 4 & 63 \\
\hline $\begin{array}{l}\text { Unit removed } \\
\text { (dry) }\end{array}$ & 4 & 59 \\
\hline
\end{tabular}

\section{B. SYSTEM \# 4}

Two transmitters and a receiver/monitor were received from the manufacturer for these tests. The transmitters seemed to have a greater output power than those tested the previous year.

System \#4 operated at a frequency of approximately $313 \mathrm{MHz}$, with the modulation occurring at approximtely 50-s intervals. The spectral characteristics of the system \#4 transmitters are shown in figures 16A through 16C. Figure 16A shows the narrowband spectrum of the transmitter, with the carrier frequency at $\sim 313 \mathrm{MHz}$. Figure 16B gives the wideband spectrum for this transmitter utilizing the maximum bandwidth of the spectrum analyzer, $1.86 \mathrm{GHz}$, in order to show more of the spectral content from the transmitter without modulation. The marker frequency, $\sim 313 \mathrm{MHz}$, identifies the fifth spike from the left as the carrier frequency. All other spikes are nominal sidelobe frequencies generated by the transmitter. Figure 16C gives the wideband spectrum from the analyzer showing amplitude modulation of the sidelobes that occurs when the signal is pulse-width modulated in the time domain. 


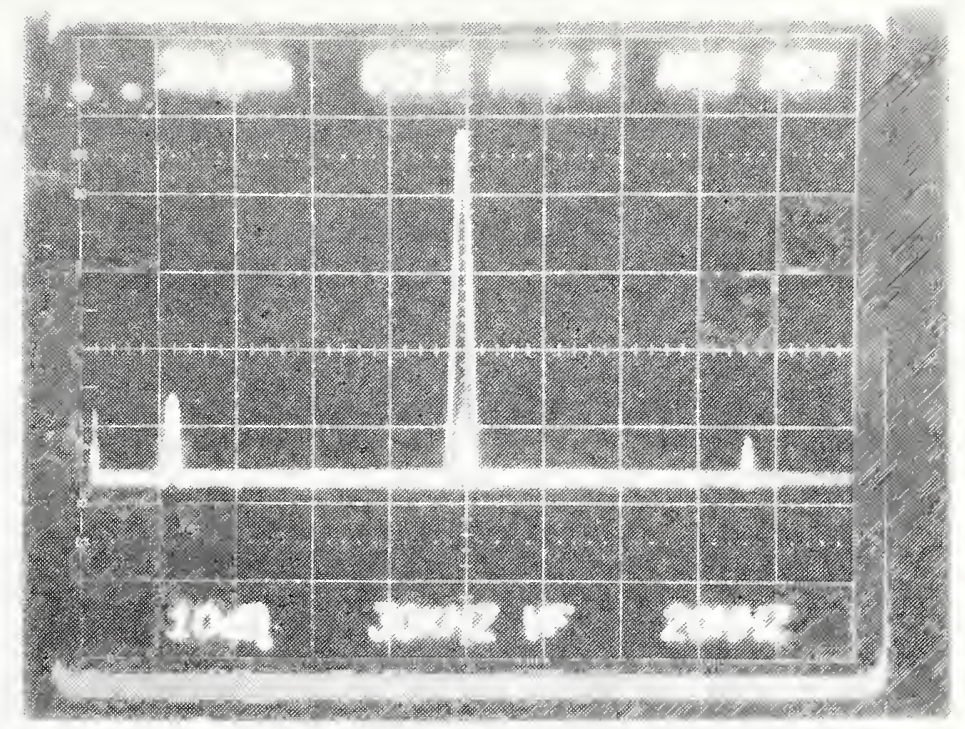

Figure 16A. Narrowband spectrum of system \#4 transmitter without modulation.

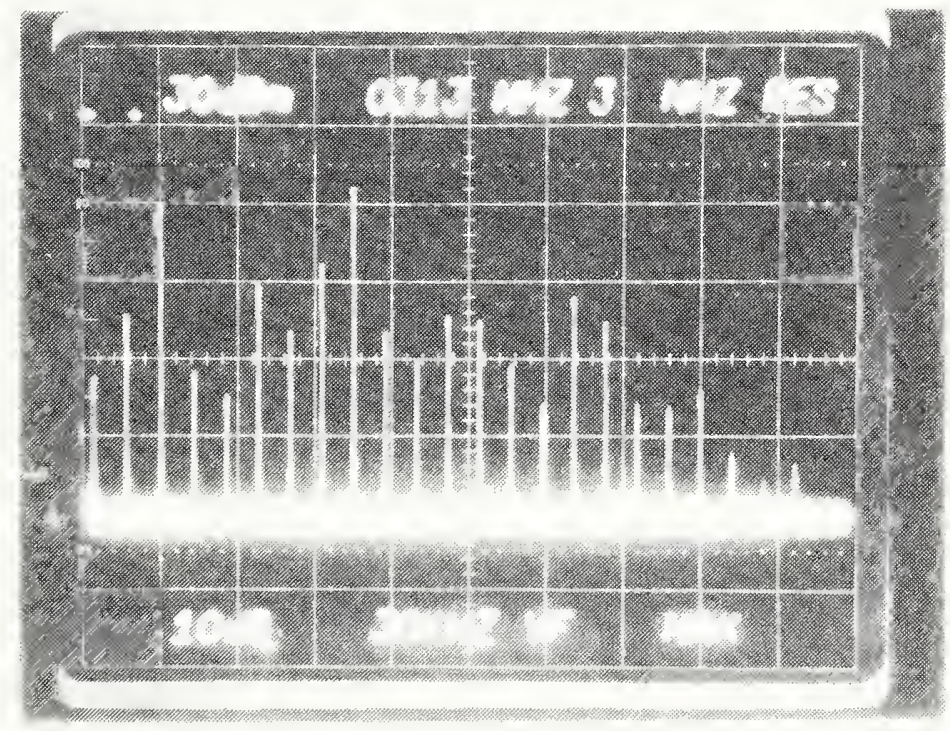

Figure 16B. Wideband modulation of system \#4 transmitter without modulation. 


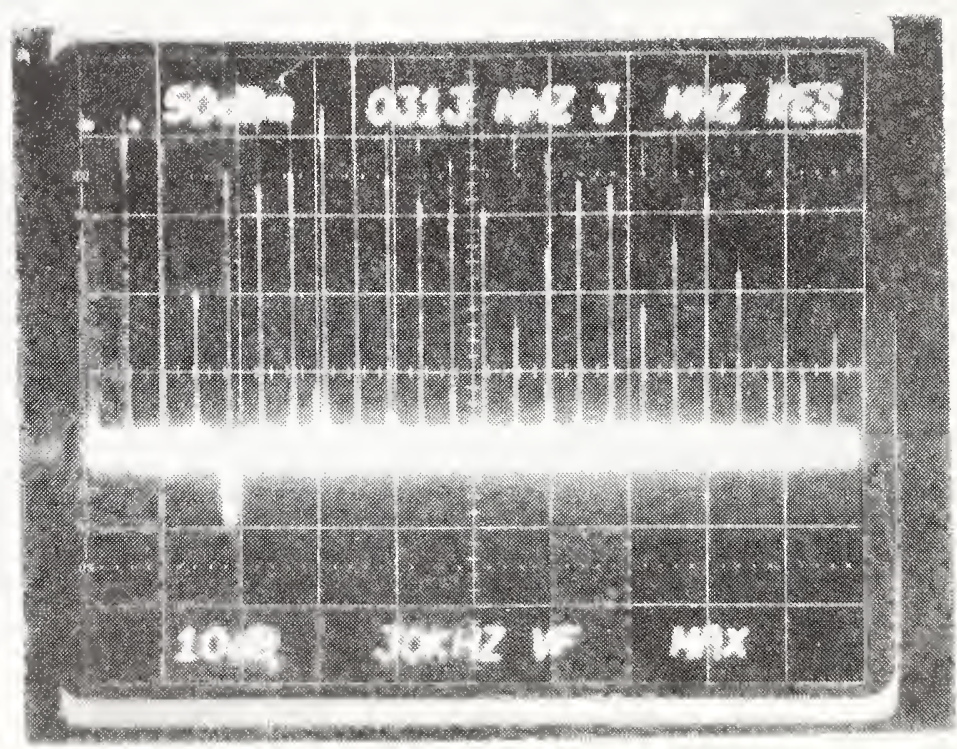

Figure 16C. Wideband spectrum of the system \#4 transmitter.

\section{$\underline{\text { Summary }}$}

System \#4 was tested on the grounds at the National Bureau of Standards (an open field test site), in a wooden residence, in a building with metal walls, and in a laboratory environment. In general, this system performed in accordance with the manufacturers specifications. As shown in table 17, range of operation measurements were made at the open field test site out to $48 \mathrm{~m}$ (157 ft), with the ankle readings only slightly lower than the readings taken from the front. Back measurements were 4-5 dB/ $\mathrm{dV}$ less than those taken at the other two positions.

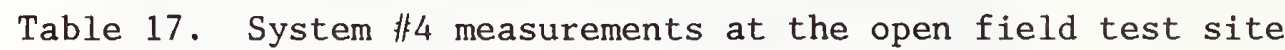

Transmitter 非1231

\begin{tabular}{cccc}
\hline & \multicolumn{3}{c}{ Location } \\
\cline { 2 - 4 } $\begin{array}{c}\text { Distance } \\
\text { (in } \mathrm{m})\end{array}$ & $\begin{array}{c}\text { Front } \\
\text { (Field }\end{array}$ & $\begin{array}{c}\text { Back } \\
\text { strength in }\end{array}$ & $\begin{array}{c}\text { Ankle } \\
\mathrm{dB} / \mu \mathrm{V})\end{array}$ \\
10 & & & \\
20 & 20 & 15 & 20 \\
30 & 15 & 10 & 13 \\
40 & 5 & 3 & 6 \\
$48(\max )$ & 4 & 2 & 3 \\
& 2 & No & 0
\end{tabular}

Transmitter 非1236

\begin{tabular}{crrr}
\hline & \multicolumn{3}{c}{ Location } \\
\cline { 2 - 4 } $\begin{array}{c}\text { Distance } \\
\text { (in m) }\end{array}$ & $\begin{array}{l}\text { Front } \\
\text { (Field }\end{array}$ & $\begin{array}{c}\text { Back } \\
\text { strength }\end{array}$ & $\begin{array}{c}\text { Ankle } \\
\mathrm{dB} / \mu \mathrm{V})\end{array}$ \\
10 & & & \\
20 & 20 & 15 & 18 \\
30 & 10 & 6 & 8 \\
40 & 6 & 2 & 4 \\
50 & 3 & 1 & 2 \\
& 1 & -2 & 0
\end{tabular}


At a range of $20 \mathrm{~m}$ (65.6 ft), the field strengths measured outside of the wooden building were $18-20 \mathrm{~dB} / \mu \mathrm{V}$, compared to $10-15 \mathrm{~dB} / \mu \mathrm{V}$ at the open field test site. See tables 18 and 19.

Table 18. System \#4 measurements at the Bowman House

Transmitter $\# 1231$

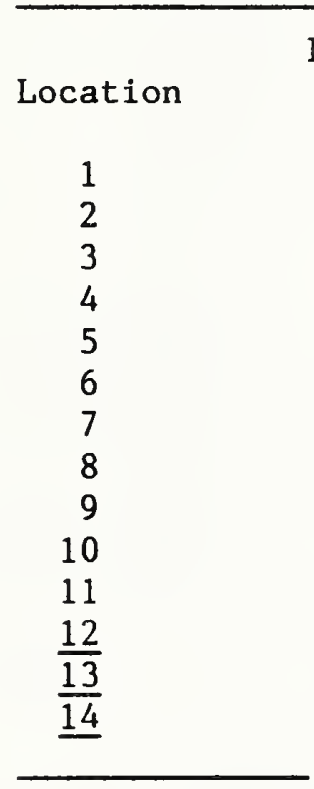

Field strength (in $\mathrm{dB} / \mu \mathrm{V}$ )

20
18
18
20
20
16
8
7
8
16
18
7
18
15

Transmitter \#1231

\begin{tabular}{cc}
\hline & $\begin{array}{r}\text { Field strength } \\
(\text { in } \mathrm{dB} / \mu \mathrm{V})\end{array}$ \\
Location & 20 \\
15 & 18 \\
$15-1$ & 20 \\
$15-2$ & 19 \\
16 & $12 / 7$ \\
$16 \mathrm{~B} / \mathrm{A}$ & 14 \\
$16-1$ & 13 \\
$16-2$ & 7 \\
17 & 4 \\
$17-1$ & 6 \\
$17-2$ & 8 \\
18 & $4 / 1$ \\
$18 \mathrm{~B} / \mathrm{A}$ & 4 \\
$18-1$ & 6 \\
$18-2$ &
\end{tabular}

12 - Underlined numbers are basement locations

15 thru 18-2 - Outside locations

$16 \mathrm{~B} / \mathrm{A}, 18 \mathrm{~B} / \mathrm{A}$ - Back and ankle measurements 
Table 19. System 非 4 measurements at the Bowman House

Transmitter 非 1236

Location

Field strength

(in $\mathrm{dB} / \mu \mathrm{V}$ )

1

2

3

4

5

6

7

8

9

10

11

$\frac{12}{13}$

$\underline{14}$
27

25

25

28

30

22

16

16

11

23

25

16

24

19
Transmitter $\# 1236$

$\begin{array}{cc}\text { Field strength } \\ \text { Location } & (\text { in } \mathrm{dB} / \mu \mathrm{V})\end{array}$

$\begin{array}{cc}15 & 18 \\ 15-1 & 14 \\ 15-2 & 18 \\ 16 & 25 \\ 16 \mathrm{~B} / \mathrm{A} & 18 / 13 \\ 16-1 & 20 \\ 16-2 & 13 \\ 17 & 6 \\ 17-1 & 5 \\ 17-2 & 8 \\ 18 & 9 \\ 18 \mathrm{~B} / \mathrm{A} & 5 / 3 \\ 18-1 & 5 \\ 18-2 & 9\end{array}$

12 - Underlined numbers are basement locations

15 thru 18-2 - Outside locations

$16 \mathrm{~B} / \mathrm{A}, 18 \mathrm{~B} / \mathrm{A}$ - Back and ankle measurements

Measurements inside the metal building produced signal strengths of 20-23 dB/ $\mathrm{dV}$ at the same distance, as illustrated in table 20 . All of these test results are similar to those encountered with system \#3, except at lower field strength levels.

Table 20. System $\# 4$ measurements in the Metrology Building

Transmitter 非1231

\begin{tabular}{cccc}
\hline $\begin{array}{c}\text { Distance } \\
\text { (in m) }\end{array}$ & $\begin{array}{l}\text { Front } \\
\text { (Field }\end{array}$ & $\begin{array}{r}\text { Back } \\
\text { strength }\end{array}$ & $\begin{array}{r}\text { Ankle } \\
\text { in } / \mu \mathrm{V})\end{array}$ \\
10 & 29 & 26 & 29 \\
20 & 23 & 20 & 18 \\
30 & 19 & 15 & 14 \\
40 & 14 & 10 & 12 \\
50 & 11 & 8 & 8 \\
60 & 7 & 3 & 5
\end{tabular}

Cross Corridor $5 \mathrm{~m} 20 \mathrm{~dB} / \mu \mathrm{V}$ $10 \mathrm{~m} 12 \mathrm{~dB} / \mu \mathrm{V}$
Transmitter 非1236

\begin{tabular}{|c|c|c|}
\hline $\begin{array}{l}\text { Distance } \\
\text { (in } \mathrm{m})\end{array}$ & $\begin{array}{l}\text { Front } \\
\text { (Field }\end{array}$ & $\begin{array}{c}\text { Back } \\
\text { strength in }\end{array}$ \\
\hline
\end{tabular}

$\begin{array}{rrrr}10 & 30 & 21 & 22 \\ 20 & 20 & 12 & 11 \\ 30 & 12 & 7 & 8 \\ 40 & 10 & 4 & 6 \\ 50 & 8 & 2 & 4 \\ 60 & 4 & 0 & 2\end{array}$

Cross Corridor $5 \mathrm{~m} 15 \mathrm{~dB} / \mu \mathrm{V}$ $10 \mathrm{~m} 9 \mathrm{~dB} / \mu \mathrm{V}$

The two transmitters operated while immersed in the water tank, but at substantially reduced power levels. However, as seen in table 21, they both returned to full strength after being removed. Radiation from typical household appliances did not interfere with the operation of this system, and the transmitters sent a coded signal when tampered 
with. The difference between the two digital signals is shown in figures 17A and 17B. Figure 17A shows the pulses of the code word during normal operation while 17B illustrates the transmission code under tamper conditions.

Table 21. System 非 immersion tests

Transmitter 非1231

\begin{tabular}{|c|c|c|c|c|}
\hline & $\begin{array}{l}\text { Distance } \\
\text { (in } \mathrm{m})\end{array}$ & $\begin{array}{l}\text { Field strength } \\
(\text { in } \mathrm{dB} / \mu \mathrm{V})\end{array}$ & $\begin{array}{l}\text { Distance } \\
(\text { in } \mathrm{m})\end{array}$ & $\begin{array}{l}\text { Field strength } \\
(\text { in } \mathrm{dB} / \mu \mathrm{V})\end{array}$ \\
\hline Reference & 4 & 40 & 4 & 42 \\
\hline Unit immersed & 4 & 34 & 4 & 34 \\
\hline for $15 \mathrm{~min}(5$ & 4 & 31 & 4 & 19 \\
\hline $\begin{array}{l}\text { min between } \\
\text { readings) }\end{array}$ & 4 & 32 & 4 & 17 \\
\hline $\begin{array}{l}\text { Unit removed } \\
\text { (still wet) }\end{array}$ & 4 & 42 & 4 & 40 \\
\hline $\begin{array}{l}\text { Unit removed } \\
\text { (dry) }\end{array}$ & 4 & 44 & 4 & 42 \\
\hline
\end{tabular}

In summary, systems 3 and 4 are improvements over the two systems previously tested. The transmitters are more powerful ( $100 \mathrm{pW}$ versus $\sim 1 \mathrm{pW})$ and have much greater range. However, in one case, the system was not able to function throughout the entire test period as three of four transmitters failed. Interference from outside sources such as other radio systems is still a problem. On several occasions testing had to be delayed until higher-powered transmitters were not in use. We cannot stress too strongly the need to pretest a given location before installing low-powered EMD systems and expecting them to operate as advertised. 


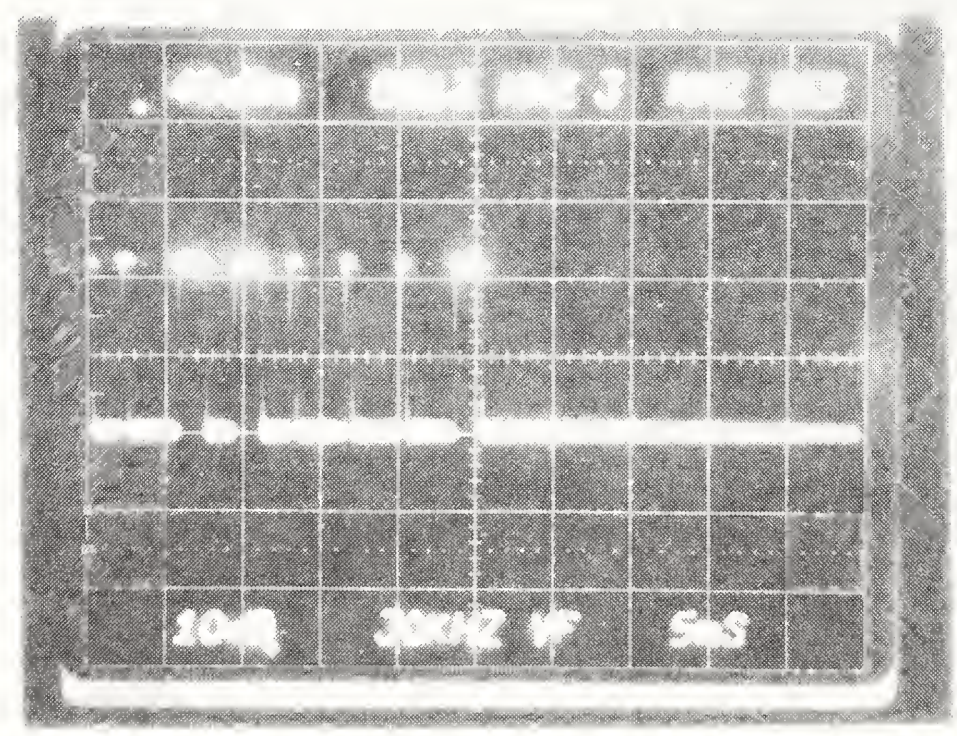

Figure 17A. System \#4 pulse code during normal operation.

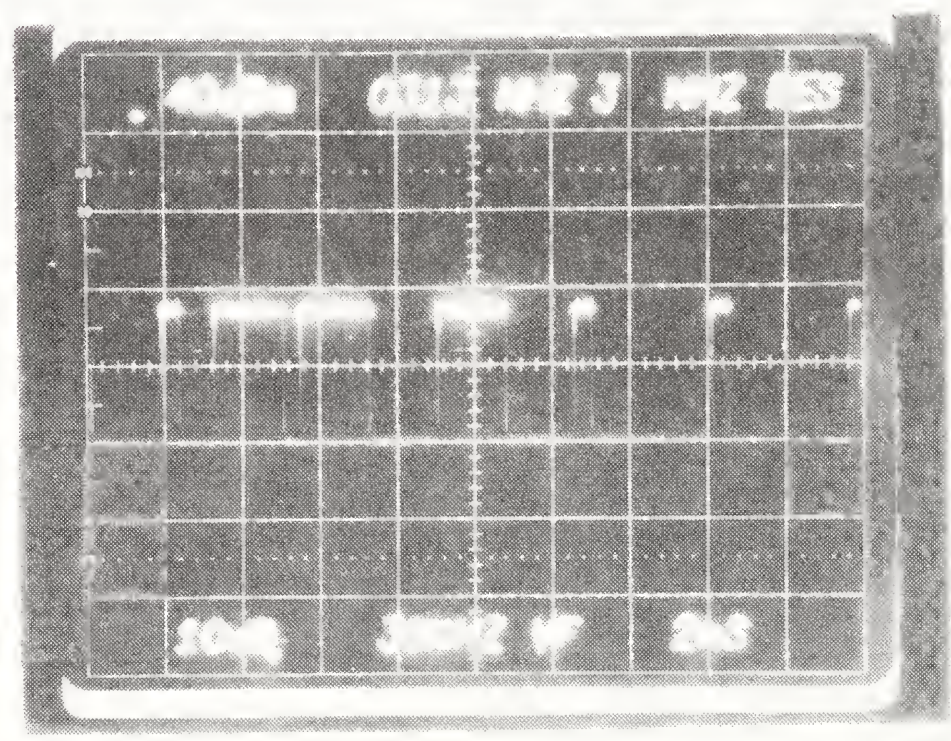

Figure 17B. System \#4 pulse code under tamper conditions. 
All four systems operated as advertised under optimum conditions. The major differences between the systems were due to the selection of a specific transmission frequency band. System \#1, operating at a lower carrier frequency than the others, had better transmission through openings and along metal corridors and had less reduction in signal level when immersed in water. The other three systems, operating at a higher frequency, had a better overall range of operation and better signal penetration through wooden structures. All were subject to loss of range capability due to body bulk or capacitance, when operated in the vicinity of broadcast transmitters operating at the same general frequency, and when immersed in water. operation along metal corridors can produce an increase in effective range along the corridor, whereas operation in the vicinity of metal objects can also cause an attenuation in signal strength in certain directions.

Users of this equipment should be informed of the above shortcomings, and potential areas of use should be checked out in advance to prevent system installation in the vicinity of unmanageable interference. Additional user testing of these systems under typical residential conditions would be helpful in determining how widespread the problem of interference might be. 
BIBLIOGRAPHIC DATA

1. PUBLICATION OR REPORT NO.

SHEET (See Instructions)
2. Performing Organ. Report No. 3. Publlcation Date

December 1986

4. TITLE AND SUBTITLE

Evaluation of Electronic Monitoring Devices

5. $A \cup T H O R(S)$

Arnold G. Perrey, Barry A. Bell, and Marshall J. Treado

6. PERFORMING ORGANIZATION (If joint or other than NBS, see instructions)

7. Contract/Grant No.

NATIONAL BUREAU OF STANDARDS

DEPARTMENT OF COMMERCE

WASHINGTON, D.C. 20234

9. SPONSORING ORGANIZATION NAME AND COMPLETE ADDRESS (Street. City, State, ZIP)

National Institute of Justice

U.S. Department of Justice

Washington, DC 20531

10. SUPPLEMENTARY NOTES

Document describes a computer program; SF-185, FIPS Software Summary, is attached.

11. ABSTRACT (A 200-word or less factual summary of most significant information. If document includes a significant bibliography or literoture survey. mention it here)

Electronic Monitoring Devices (EMDs) are used to monitor the presence of individuals within a given area who are responsible to the criminal justice system but not confined to institutions. Several EMDs were tested to measure operational characteristcs such as operating frequency, approximate range of operation, component capability, and tamper resistance. Tests were conducted in an open field, wooden residence, high rise metal building, and in a laboratory environment.

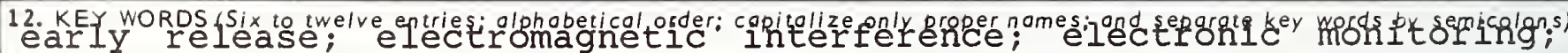
monitoring device; parole; receiver/monitor; tamper resistance; transmitter

13. AVAILABILITY

[X] Unlimited

— For Official Distribution. Do Not Release to NTIS

$\square$ Order From Superintendent of Documents, U.S. Government Printing Office, Washington, D.C. 20402.

$\left[\begin{array}{l}\mathrm{X} \\ {[}\end{array}\right]$ Order From National Technical Information Service (NTIS), Springfield, VA, 2216I
14. NO. OF PRINTED PAGES

15. Price

$\$ 13.95$ 



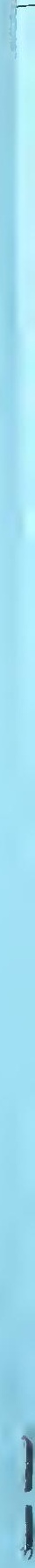

